\title{
Sobre la representación de ciudades marítimas en mosaicos romanos
}

\author{
M. ${ }^{a}$ LUz NeIRA JIMENEZ
}

\section{RESUMEN ABSTRACT}

Representaciones de ciudades

maritimas no son demasiado frecuentes en la musivaria romana, donde, en contraste con las documentadas especialmente en relieves y pinturas, los testimonios conservados suelen corresponder a vistas parciales que muestran algunos

edificios y/o sus instalaciones portuarias. Sin embargo, a través de su análisis se aprecia una gran diversidad, aunque en la mayoría predominan edificios, bien documentados ya en obras de época helenistica.
Seaside town are not usually represented on roman mosaics, the, in contrast to the representations specially documented on reliefs and pictures, present partial views, some architectural constructions and/or ports. However, an analyse show a great diversity, although in most cases are predominated the buildings, documented in hellenistic age.

A pesar del gran número de ciudades marítimas existentes en el Imperio Romano y del importante papel que estas urbes tuvieron en aquelia época, no son demasiadas las representaciones documentadas en la musivaria romana '. Éstas son en su mayoría vistas parciales que suelen limitarse a una serie de edificios supuestamente pertenecientes a un conjunto urbano y/o a sus instalaciones portuarias.

No incluimos en este estudio las alegorias y personificaciones de ciudades maritimas al constituir otro género de representaciones. 
Al margen de estas características se encuentra, no obstante, la representación del mosaico bícromo que pavimenta el frigidarium de las termas de los Cisiarii en Ostia (Fig. 1), del 120 d.C. ${ }^{2}$. Se trata de un recinto amurallado, que delimita una planta urbana de forma cuadrada, con cuatro puertas de acceso situadas en el centro de cada lado y cuatro torres en los extremos ${ }^{3}$. Tres de las puertas tienen doble hoja y dos pisos, mientras que la cuarta, sobrepasando igualmente en altura el muro continuo, presenta un gran arco y, sobre éste, dos hiladas superpuestas. Las torres superan también la elevación de los muros, tal y como aconsejaba Vitrubio (De archit. I, V) ${ }^{4}$ "con el fin de que desde las torres, a derecha e izquierda, los enemigos puedan ser heridos desde ambos lados con armas arrojadizas, cuando intenten acercarse violentamente a la muralla", y son cilíndricas, "pues si las torres son cuadradas las máquinas de guerra las

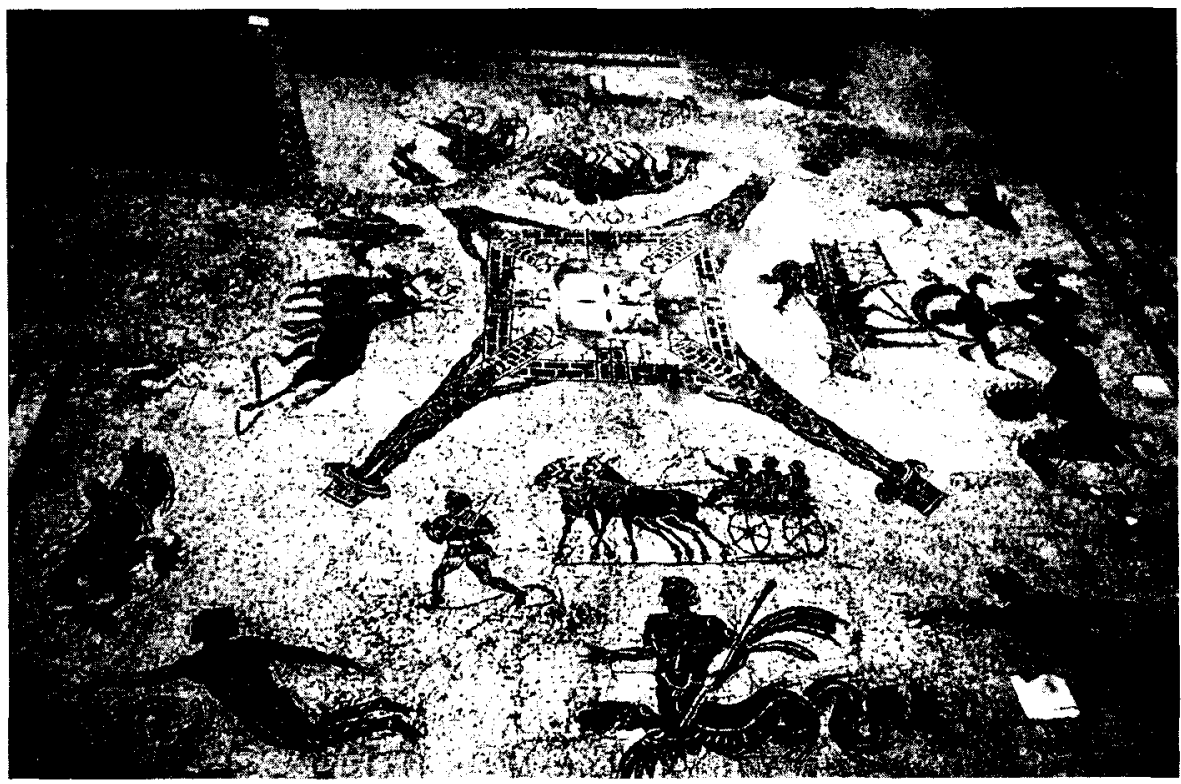

Figura 1. Mosaico de las termas de los Cisiarii (Ostia). Foto del autor.

G. BfCattl, Scavi di Ostia. IV Mosaici e pavimenti marmorei. Roma 1961, núm. 64, págs. $42-44$.

El recinto amurallado ocupa aquí el centro del campo del mosaico, aunque fue más frecuentemente utilizado como motivo de enmarque sin relación explícita con la representación de una ciudad. Véase más adelante, cf. nota 7.

Vitrubio. Los diez libros de Arquitectura, con introducción de D. Rodpiguez Ruiz y traducción de J.L. Olive h Domingo, Madrid 1995, Alianza Forma n" 133. 
destruyen con toda facilidad, ya que los arietes rompen sus ángulos con sus golpes, mientras que si son circulares, con piedras en forma de cuña, aunque golpeen su parte central no pueden dañarlas». Sin embargo, en la planta del recinto no han sido tenidas en cuenta las directrices de Vitrubio, quien recomendaba la forma circular "con el fin de observar al enemigo desde distintos puntos».

Como elementos sustentantes, cuatro figuras de telamones representados de pie sobre un capitel soportan sobre sus cabezas la base de las torres y, con los brazos alzados, sujetan con ambas manos los muros del recinto. En los espacios resultantes entre los telamones, extramuros, se disponen de cara al exterior cuatro representaciones alusivas a la corporación de los Cisiarii, titulares de las termas. Se trata de escenas que documentan el transporte en carros tanto de personas como de mercancias, actividad de vital importancia entre el puerto de Ostia y Roma ${ }^{5}$.

En los bordes del campo y también orientadas al exterior sobre los lados norte, este y oeste se conservan representaciones indicativas del ambiente marino. En el lado oeste un eros alado, muy dañado, aparece de pie sobre un delfín tras una representación del dios Neptuno, en pie sobre las colas pisciformes de dos hipocampos que avanzan hacia la izquierda, según uno de los tipos iconográficos más en boga durante gran parte del siglo II d.C. ${ }^{6}$. En el lado norte destaca en el centro la figura de un tritón de aletas natatorias, que, aún con el torso casi de frente, avanza también hacia la izquierda portando una vara, y en los flancos dos figuras de natantes, dos jóvenes completamente desnudos, estando precedido el de la izquierda por un delfín. Por último, en el lado este un par de delfines, también hacia la izquierda, avanzan tras la aleta caudal de otra representación marina, afectada por una laguna que se cierne sobre gran parte del pavimento. Finalmente, el campo del mosaico aparece enmarcado por una orla de murallas ${ }^{7}$ que muestra un esquema muy similar al utilizado en la representación central.

\footnotetext{
El hecho de que los carros figuren representados fuera del perímetro de la ciudad podria responder a una simple cuestión de espacio en la composición del mosaico, aunque también podria aludir a la prohibición que desde época tardorrepublicana regía sobre la ciudad de Roma. normativa ampliada a otras ciudades en época imperial.

A este mismo tipo, sin carro, pertenecen las conocidas representaciones de Neptuno en los mosaicos también bicromos de las termas de Neptuno en Ostia y de Risaro, fechados en los años próxímos a mediados del siglo $\|$ d.C., G. BtCATII, op. cit., núm. 70: J.R. ClaRkE, Roman black-and-white figural mosaics, Nueva York 1979, pág. 24, figs. 26-27. Sobre los distintos tipos iconográticos de Neptuno en la musivaria romana, véase también M.L. NFIRA, "La tipologia del carro en los mosaicos romanos del "Triunfo" de Neptuno", L Africa romana. Atti del XI Convegno Internazionale di Studio, vol. I, Sassari 1996, págs. 555-576, + tavv. L-XV, esp. 555-556.

La denominada "orla de murallas" aparece ya en mosaicos helenísticos como el hallado en Arsameia, cf. J. Bal TY, "La Mosaique au Proche-Orient 1", ANRW II, 12, 2, 1981, Iáms. II, 1- 2, y
} 
Las figuras relacionadas con el mundo marino, cuya orientación de cara al exterior y avance en una misma dirección son rasgos comunes a otras representaciones de thiasos marino ${ }^{8}$, aparecen sobre un fondo neutro de teselas blancas, sin trazos indicativos del agua. Sin embargo, es de reseñar que en la mayoria de las representaciones más antiguas de cortejos marinos en los mosaicos bícromos de la Península Itálica es caracteristica la ausencia explícita de signos alusivos al agua ${ }^{9}$. En este contexto, son las propias imágenes de Neptuno, el tritón, los natantes, el eros $y$, en suma, de los delfines, las que, lejos de figurar como añadidos mitológicos sin relación con el tema central - la ciudad amurallada y los carros de transporte-, deben ser consideradas como representaciones indicativas del ambiente marino y concretamente, al aparecer bordeando la ciudad en cuestión, como elementos alusivos al carácter marítimo de la ciudad.

En este sentido, tanto el lugar de procedencia del mosaico, como la conjugación de los cisia, en clara relación a su papel en el transporte de las mercancias Ilegadas al puerto y su traslado a Roma, y de las figuras marinas alusivas al carácter marítimo de la ciudad inducen a pensar que la representación genérica del recinto amurallado es, en realidad, una representación simbólica de Ostia.

Sin embargo, tal y como apuntábamos al principio, la representación urbana del mosaico ostiense no es un prototipo seguido en la musivaria romana y ni siquiera se documenta la figuración de murallas, aunque fuera con otra perspectiva, en el resto de las representaciones de ciudades ${ }^{10}$,

está bien documentada en varios pavimentos de los primeros siglos del Imperio, cf. J.M. BLAZQUEZ et alii. Mosaicos romanos de Navarra. CME VII. Madrid 1985, págs. 54-55.

Sin ir más lejos en un buen número de las documentadas en otros mosaicos bícromos ostienses (G. BECAIII, op. cit.), asi como en numerosos pavimentos bicromos y polícromos de la $P$ nínsula Itálica y del resto del Imperio. Generalmente son los miembros habituales de un cortejo marino, tritones, monstruos marinos y nereidas representadas sobre unos $u$ otros, así como diversas especies marinas reales, los que figuran en torno al centro del campo, bien en función de una representación principal, bien como protagonistas de la composición. Sin embargo, en el mosaico de las termas de los Cisiarii se ha incluido entre ellos a Neptuno, aunque ya en pavimentos inmediatamente posteriores la representación del dios ocupará un lugar destacado en el centro de la composición, en torno al cual se dispondrá el cortejo, cf M.L. NEIRA, op. cit., pajgs. 555-576.

Véase a modo de ejemplo, muchos de los mosaicos ostienses (G. Becalli, op. cit).

Sirva como excepción la representación de un mosaico parietal que decora parte de los muros de la nave de Santa María la Mayor en Roma, basilica construida y decorada bajo el papado de Sixto III entre los años 432-440 d.C. (X. Barkal I Aliet et alii. II. Mosaics, Nueva York 1989. pág. 64), donde. entre las escenas del Antiguo Testamento. ilustrando el "Paso del Mar Rojo". se sitúa una ciudad sobre una colina costera. La ciudad aparece rodeada por una gran muralla con monumental arco de acceso, de cuyo recinto interior sobresale la parte alta de algunos edificios dotados de frontón y cubiertas a dos aguas, según la tendencia apreciada en cambio en pinturas y relieves romanos (cf. R. TuRCAN, $L$ Art Romain dans I'Histoire. Six siecles d'expressions de la Romanité. Paris 1995, figs 32 y 77) y en posteriores representaciones de época bizantina. 
sean o no sean marítimas. Para ello habrá que esperar a los testimonios conservados en mosaicos de época bizantina, del siglo vi d.C. en adelante, donde ademas del recinto amurallado han sido incluidos los edificios más significativos de la ciudad representada ${ }^{1}$.

A una concepción, por tanto, distinta pertenece la representación conservada en tres grandes fragmentos de un mosaico policromo que en origen pavimentaba una sala de recepción de una casa en El Alia, en torno al 120-130 d. C. ${ }^{12}$. A pesar de su estado fragmentario y de la discutida disposición de los fragmentos conservados en el Museo de El Bardo puede advertirse que se trata de un paisaje costero contemplado desde el agua, que ocupa el primer plano de la composición y la mayor parte de ésta, mientras diversos edificios situados en la costa figuran en un segundo plano en la parte superior del mosaico. El movimiento del agua, cuya superficie se encuentra bien delimitada por la línea de costa, está indicado además por diversos trazos paralelos en sentido horizontal que reproducen mediante teselas cuadradas dispuestas sobre la punta líneas dentadas y, en menor número, siluetas almenadas, tal y como es frecuente en muchos mosaicos de tema marino ${ }^{13}$. Su representación corresponde a un punto de vista considerablemente elevado, sin conexión con las distintas especies marinas, incluido un delfín, que, aún figurando en el agua, responden en cambio a una visión aérea vertical, idéntica a la que se tendria de ellas si hubieran permanecido tendidas, ya sin vida, sobre la arena ${ }^{14}, y$ sin relación con los personajes, que tanto en barcas o a pie en distintas

A este respecto, aparte del rico repertorio que aparece en el famoso mosaico-mapa de Madaba, véase en este mismo volumen el artículo de G. Lopk 7 Montr Acudo, son numerosas las representaciones de ciudades en mosaicos hallados en la mitad oriental del Mediterráneo, cf. también EADEM, "Modelos clásicos para las pinturas de San Isidoro de León", Actas de las $V /$ Jornadas de Arte "LA VISIÓN DEL ARTE CLASICO EN EL ARTE ESPAÑOL". Madrid, 1993. págs. 25-35, figs. 1-29.

P. Gaucktth, Inv. Mos. Af. (TInisie), Paris 1910, págs. 39-41; L. Foucher, "Les mosaiques nilotiques africaines". CMGR I. París 1965, págs. 137-144, figs. 4, 13 y 15; G. Ch. PICAFio. "Mosaiques et société daos I'Afrique romaine. Les Mosalques d'El Alia (Tinisie)». L'Afrique dans l'OCcident Romain, Roma 1990, pags. 3-14; G. LOPf 7 MONTEAGuoo, "Representaciones de ciudades en mosaicos romanos del Norte de Africa". L Africa romana X. Sassari 1994, págs. 1241-1257, fig. 2 , tav. VI, 1-2

Se trata de uno de los procedimientos más utilizados, aunque no el único, ya que, como hemos apuntado anteriormente, el agua puede figurar implicitamente como un fondo neutro o expresamente indicado mediante trazos discontinuos, dispuestos tanto en sentido paralelo como perpendicular, simulando el cierre de un paréntesis, o mediante lineas continuas.

Sobre la perspectiva utilizada en la representación de paisajes en mosaicos y la combinación de varios puntos de vista en una composición, véase M.L. Ni IFA, "El paisaje y sus representaciones en la musivaria de la Antigüedad", Actas del Congreso "Visiones del Paisaje" (Priego de Cordoba, Córdcba), nov. 1997, Madrid 1998, notas 16-21. 
actividades relacionadas con la pesca figuran desde un punto de vista frontal ${ }^{15}$.

En tierra firme, los edificios aparecen desperdigados sobre un fondo neutro, del que sobresalen como elementos propios de la vegetación ambiental varios tipos de árboles y, en este sentido, algunos autores ${ }^{16}$ lo interpretan como escenas propias de las extensas propiedades que muchos domini poseían en las costas norteafricanas, a semejanza de aquellas otras villae situadas en el interior, de las que se conservan magníficas representaciones en varios mosaicos romanos del Norte de Africa ${ }^{17}$. Efectivamente, el terreno en el que se insertan las construcciones podría sugerir un ambiente rural, sin embargo también podría interpretarse como perteneciente al territorio de una ciudad. Igualmente algunos edificios podrían relacionarse con las mansiones de los domini representadas en otros pavimentos. Nos referimos a

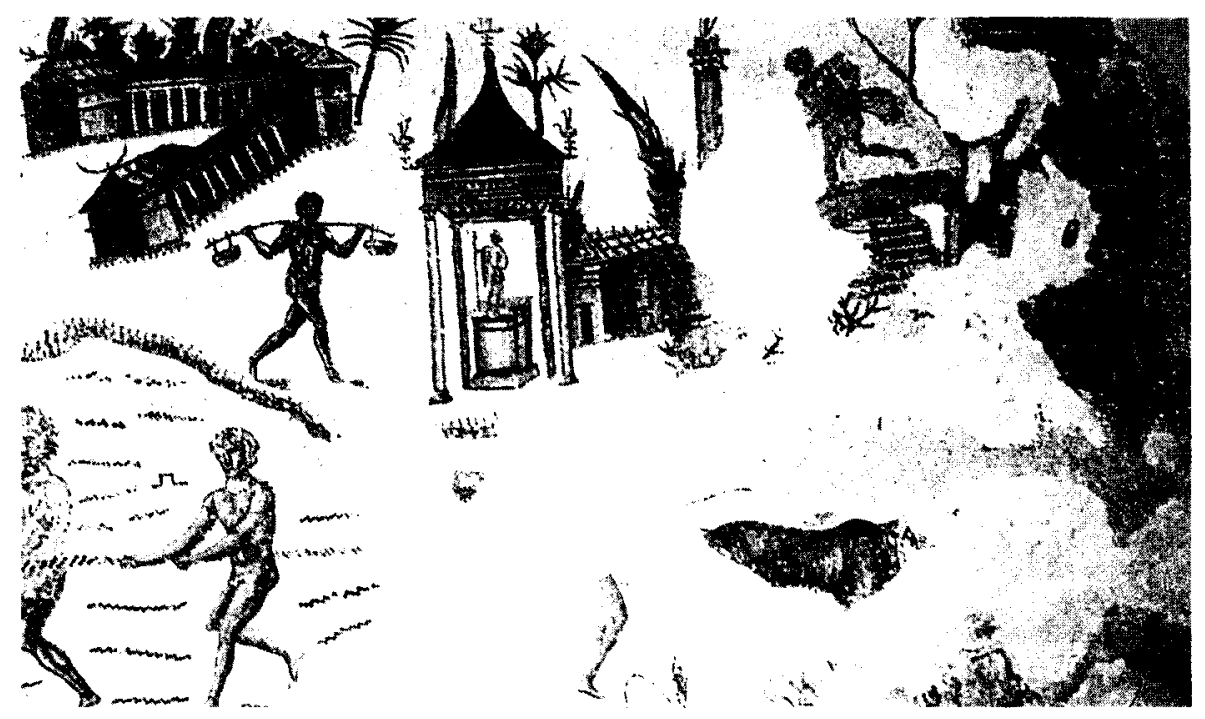

Figura 2. Mosaico de El Alia. Detalle. Foto: Según M. Fantar et alli

Aunque se suele tildar de poco hábiles a los artistas de la Antigüedad, creadores de éstas u otras obras similares, es preciso resaltar que en estas composiciones prima el interés por mostrar con claridad las diversas figuras, objetos y actividades representadas en el mosaico, y con este fin parece haberse recurrido a la combinación de varios puntos de vista, el más apropiado para cada representación. sin reparar tanto en la perfección de una visión única y acorde con la óptica real.

M. Fantar et alii, La Mosaïque en Tunisie, París-Túnez 1994, págs. 130-133.

T. SARNOWSK, Les representations de villas sur les mosaïques atricaines, Varsovia 1978; J.M. BlAzQueZ, "El entorno de las villas en los mosaicos de Átrica Hispania". L'Africa Romana $X$ Sassari 1994, págs. 1.171-1.187, tav. |-XVI. 
una construcción conservada en el fragmento mayor, con planta en forma de $U$ invertida, compuesta por un bloque central retranqueado y dos alas de galerías porticadas que desembocan en sendos pabellones, coronados en la cima del frontón, correspondiente a la cubierta a dos aguas, con una cornamenta de ciervo de carácter profiláctico (Fig. 2); igualmente otro edificio situado en el extremo izquierdo del que sólo resta una torre, próximo a otro de cubiertas abovedadas, que identificamos con un establecimiento termal, probablemente perteneciente al mismo conjunto (Fig. 3); e incluso las chozas de planta circular y cubierta cónica de mimbre, que, como vivienda de los trabajadores, bien podrían inscribirse en el ambiente rural de las villae; a pesar de que no hay que olvidar ia semejanza entre las domus situadas en la ciudad y las residencias señoriales de las villae.

La comparación, no obstante, con las representaciones de villae y concretamente de la casa señorial en los mosaicos norteafricanos refleja que la mansión principal del dominus, incluso con independencia del lugar más o menos destacado que ocupe en la composición, bien en el centro del campo ${ }^{18}$, bien en un extremo al situarse como punto de partida de una jornada cinegética ${ }^{19}$, es el único edificio de la villa representado en alusión al gran do-

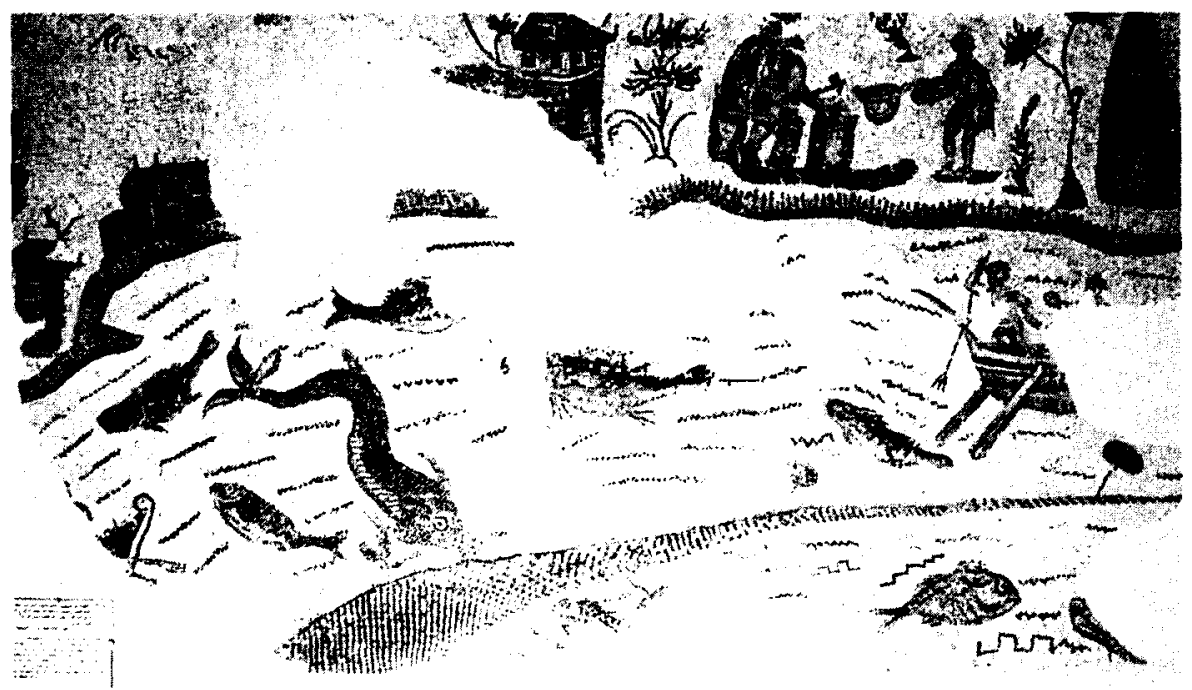

Figura 3. Mosaico de El Alia. Detalle. Foto: Según M. Fantar et alli.

Entre otras. la del dominus lutius en Carthago, ibidem, figs. 18-20: M. BLANCHAHO-LEMEE, Sols de l'Afrique Romaine. Paris 1995, fig. 121; y las representaciones de mosaicos de Tabarca.

En otro pavimento de Carthago. M. Yacoub. Le Musée du Bardo. Túnez 1993, fig. 113. 
minio ${ }^{20}$, y a ésto hay que añadir la existencia en el mosaico de otras construcciones arquitectónicas, más propias de una ciudad que de una villa.

A este respecto, en el extremo derecho, próximo a la construcción de planta en forma de $U$ invertida, se conserva aunque muy deteriorado un edificio porticado de forma semicircular con torres en los extremos (Fig. 2), que reproduce la planta de algunas representaciones de puertos, particularmente en monedas de Nerón, Antonino Pío, Caracalla y Galieno ${ }^{21}$, y parte de un puente, ya con la misma orientación que el resto de las edificaciones, sobre el que aparece cruzando un personaje. A continuación, una columna sobre la que se erige una estatua, en segundo plano un edificio con tejado a dos aguas $y$, de nuevo en primer plano junto a la línea de costa, un edículo tetrástilo con cubierta a cuatro aguas ${ }^{22}$ que preserva en su interior un ara

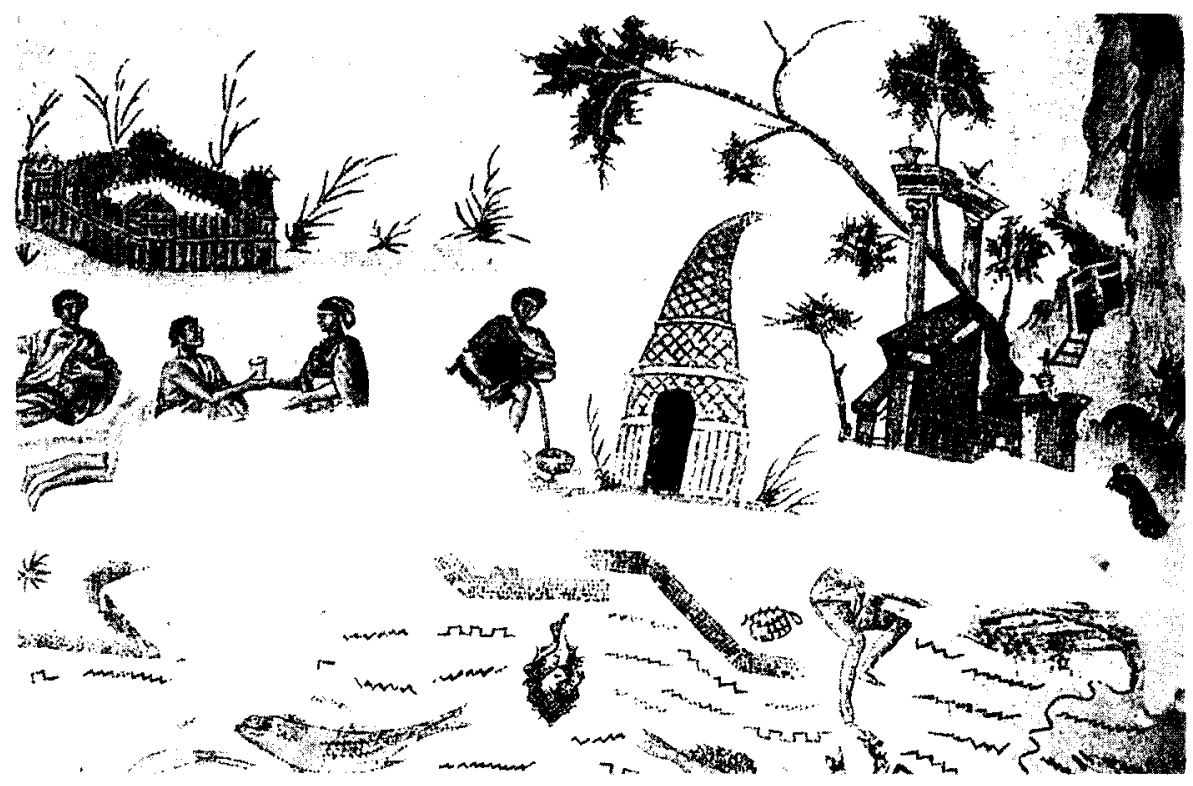

Figura 4. Mosaico de El Alia. Detalle. Foto: Según M. Fantar et alli.

En este sentido. el evidente interés de cada uno de aquellos potentados que encargaban un mosaico con la representación de su supuesta villa. como simbolo de su prestigio, choca frontalmente con la idea de concebir una decoración basada en un paisaje costero, que reflejara diversos dominios maritimos pertenecientes a distintos propietarios.

K. Lehemann-HaRtl.tben. Die antiken Hafenanlagen des Mittelmeeres, Wiesbaden 1963. núms. $1,5,9$ y 11 .

Edículos de las mismas caracteristicas figuran representados en una pintura de paisaje sacro-idílico. fechada en el año 70 d.C., que se conserva en el Museo Nacional de Nápoles 
destinada a servir de basamento a la estatua de una divinidad que por su tridente debe ser identificada con Neptuno ${ }^{23}$, siendo muy frecuente la ubicación de estatuas de divinidades sobre aras y columnas en escenarios portuarios, según se documenta en numerosas pinturas de época temprana, como el conocido paisaje portuario de Stabiae ${ }^{24}$, donde varias estatuas sobre columnas se alzan en unos muelles sobre arcadas.

Prosiguiendo de derecha a izquierda aparece la citada construcción provista de bloque central y alas porticadas, asi como un edificio dístilo, una choza $y$, en un segundo plano más al interior, un recinto fortificado que se asemeja a un campamento (Fig. 4).

En otro de los fragmentos (Fig. 5) se encuentra representado un edificio de varios pisos, al menos tres, junto al que aparece de pie un personaje

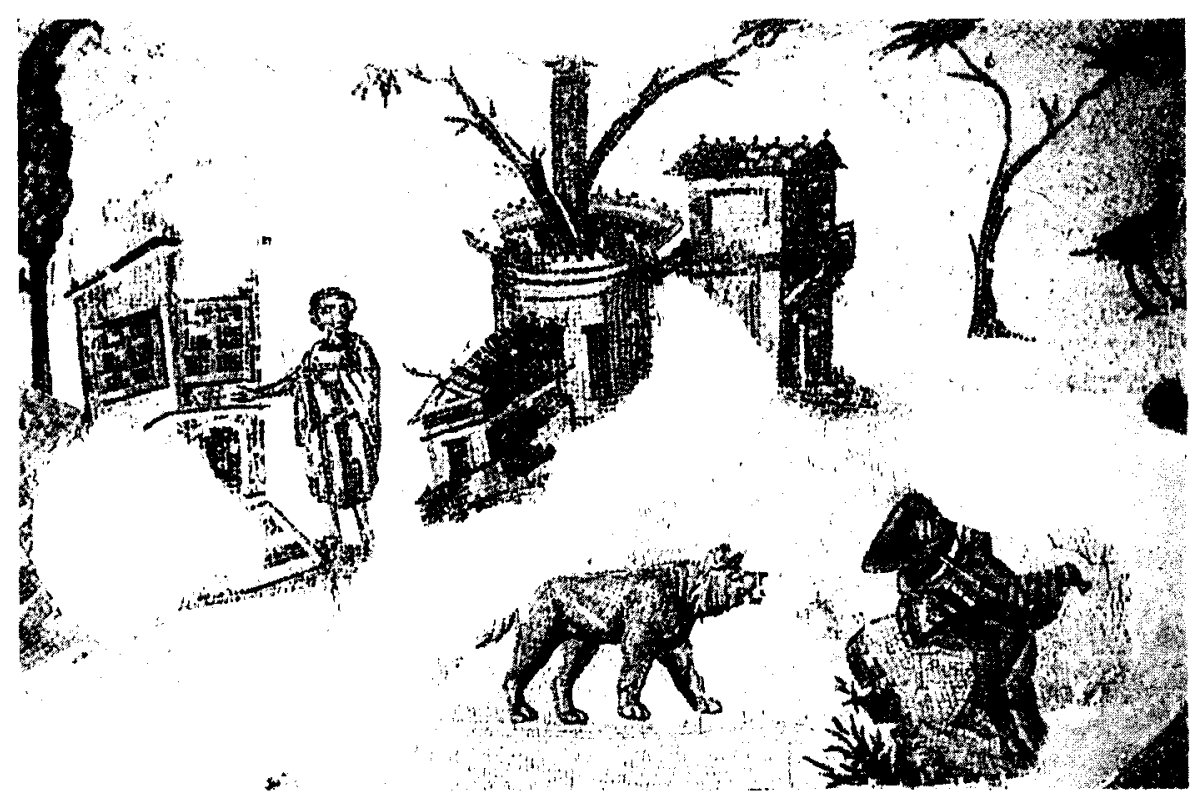

Figura 5. Mosaico de El Alia. Detalle. Foto: Según M. Fantar et alli.

(R. TuRcan, L Ant Romain..., fig. 73). donde uno de éstos edificios tetrástilos parece contener en su interior un árbol. probablemente sagrado

La representación de estatuas de Neptuno sobre un ara está igualmente documentada en varios mosaicos, donde el dios aparece flanqueado por miembros habituales del thiasos marino. véase M.L NEIRA, "La tipología del carro en los mosaicos romanos del Triunfo de Neptuno"..., pág. 555, nota 2.

\% G. LOPEZ MONTEAGIJOO, "Representaciones de ciudades en mosaicos romanos del Norte de África", LAfrica Romana X, Sassari 1994, tav. XII, 1. 
sin guardar las debidas proporciones. El edificio, que al haber sido reflejado con un punto de vista angular muestra la fachada principal y uno de los laterales, responde a una planta cuadrada, posee una ventana también cuadrada en cada lado del segundo piso y presenta unos peldaños de acceso a la puerta con forma de arco que da paso al interior. Muy cerca, dos pabellones formando ángulo, uno de dos plantas con balconada en el superior y tejado a doble vertiente y otro de altura difícil de precisar por la laguna que afecta a su parte baja. Parecen unidos por una construcción de planta circular, de cuyo interior, al carecer de techumbre, sobresalen dos gruesas ramas de un árbol, idéntico a algunos de los ejemplares representados en el mismo mosaico, y una gran columna, sobre la que se cierne una laguna. A pesar del deterioro que afecta a esta singular edificación, es posible apreciar un vano estrecho y rectangular en el muro, por lo demás cerrado, y, con un diámetro mayor, la cornisa almenada que resalta en la zona superior.

Considerando que incluso construcciones similares de forma cilindrica sin techumbre son poco habituales, -aunque podrian identificarse, máxime en escenarios costeros y portuarios, como torres de vigilancia ${ }^{25}$ - es digno de señalar la excepcionalidad de este edificio que, figurando como recinto en el cual se inscriben un árbol y una columna, no aparece documentado en el conjunto de mosaicos romanos. Sin embargo, sí encontramos una representación idéntica en una pintura romana que decoraba una de las estancias de una casa o villa descubierta bajo la iglesia de San Sebastián en la via Appia, fechada hacia el año 180 d.C. ${ }^{26}$. El fresco (Fig. 6) reproduce un paisaje portuario y muestra en uno de los extremos de unas arquerías inmersas en el agua una construcción igualmente cilindrica, que, situada en tierra firme, presenta un vano adintelado y de considerable altura para acceder al interior, así como pequeñas ventanas con forma de arco en la zona superior, mientras, careciendo también de techumbre, un frondoso árbol y una gran columna, cuyo capitel sirve de base a una majestuosa estatua, sobresalen de su interior.

En este sentido, y a pesar de que también son numerosas las representaciones de columnas sobre las que figuran ánforas, escudos u otros objetos de bronce en diversos paisajes marítimos y portuarios reflejados en pinturas helenísticas y romanas ${ }^{27}$, la estrecha similitud entre los dos

\footnotetext{
Véase más adelante lo relativo al mosaico hispano de la Vega Baja de Toledo.

R. Bianchi Bandinelli, Roma. Centro del Poder, Madrid 1970, fig. 334

J. Chabonnealux et alii, Grecia helenistica, Madrid 1971; R. TuRcan, L'Art Romain.., figs. 69 


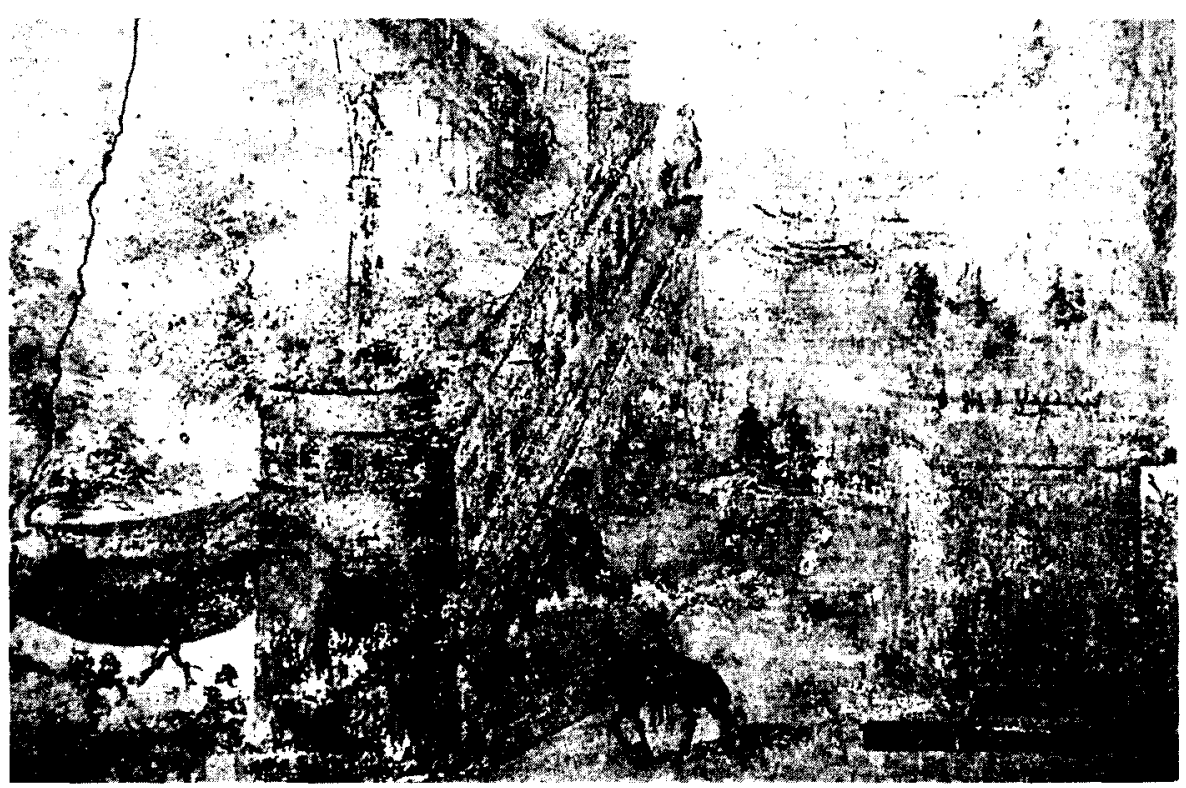

Figura 6. Pintura de una casa romana, hallada bajo la basilica de San Sebastián. Foto: Según R. Bianchi-Bandinelli.

edificios cilíndricos documentados en el fragmentario mosaico de El Alia y el tresco de la Via Appia nos induce a pensar que también una estatua debió erigirse sobre la columna de la construcción cilíndrica representada en el pavimento africano, lo que evidenciaría la existencia real de un tipo de edificación propia de ambientes portuarios. En esta línea, aunque ni las fuentes literarias ni arqueológicas parecen ofrecer testimonios sobre la funcionalidad de estos edificios, el hecho de que el recinto circular inscriba en su interior un árbol y una columna podría reflejar el deseo de preservar quizás un árbol considerado como sagrado por determinadas circunstancias ${ }^{28}$, así como la delimitación de un recinto igualmente sagrado al albergar la estatua de una divinidad protectora de las actividades que tenían lugar en un contexto marino. Este es el motivo que podría desprenderse de la representación contenida en una moneda alejandrina (Fig. 7), que ha sido tradicionalmente interpretada como símbolo, aunque irreal, del faro de

28 A este respecto, es de sobra conocida la consideración que para los antiguos tenía aquel lugar en el que se suponia había caído un rayo, y es de destacar la representación similar de edículos tetrástilos preservando en su interior un árbol que se documenta en una pintura ya citada. cf. nota 22 . 


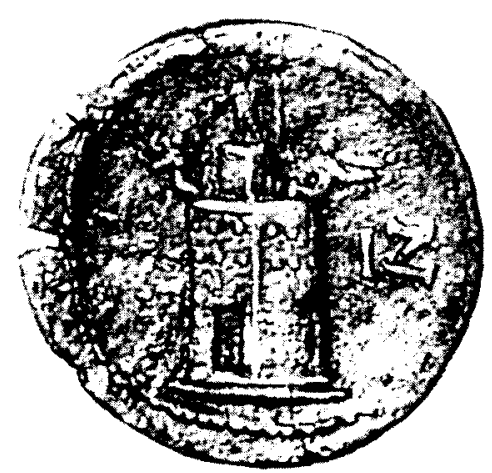

Figura 7. Moneda alejandrina. Foto: Según LIMC.

Alejandría ${ }^{29}$. A juzgar por la consideración de que ni incluso todas las torres situadas en escenarios costeros debieron ser en realidad auténticos faros ${ }^{30}$, la representación de la citada moneda muestra un edificio de planta circular y alzado cilíndrico - también con vano de acceso adinteladosobre el que se ha pretendido ver otra estructura cilíndrica de menor diámetro, a modo de segundo cuerpo, coronada por una estatua de Neptuno, si bien, a nuestro juicio, esta representación podría estar en realidad reflejando una construcción cilíndrica que contendria en su interior una columna, como soporte de la estatua de Neptuno ${ }^{31}$.

Sin embargo, la representación conservada en los fragmentos de El Alia no sólo contempla la exposición de diversos edificios que pudieron ser significativos en las ciudades marítimas, sino que debe ser entendida como una gran combinación genérica de la arquitectura urbana de la costa y las actividades propias de sus habitantes, al incluir no sólo referencias evidentes a las tareas de la pesca, sino también al salpicar el paisaje costero de otras representaciones relativas a la vida cotidiana en una ciudad, como la traída de agua, el empleo de los animales en diversos menesteres, el taller del herrero o la distendida charla de algunos personajes junto a la orilla del mar.

LIMC, VIII, s.v. "Tritones", num. 51. A pesar de que ninguna de las hipotesis planteadas sobre la estructura original del Faro de Alejandría, (véase sobre este particular, M. REDDE, "La représentation des phares a l'époque romaine". Mefra 91. 1979, págs. 845-870), concuerda con la imagen reproducida en la citada moneda

Sobre la tradicional confusión en torno a las torres costeras, M. REDDF, op. cit., pags. 845-858, quien rechaza su interpretación generalizada como representaciones de faros y refiere la diversa finalidad de distintas torres.

Los tritones, que según la tradición figuraban en el Faro de Alejandría, podrían en este caso haber formado parte de una decoración escultórica asociada a la cornisa del edificio. 


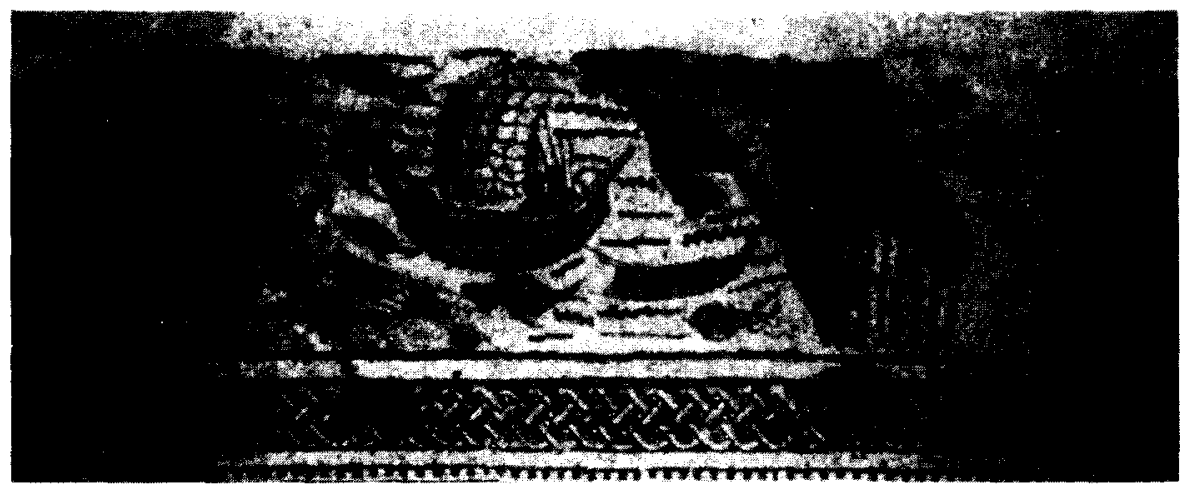

Figura 8. Fragmento del mosaico de Hippo Regius. Foto: Según Marec.

Menos abstracta parece, en cambio, otra representación conservada en un mosaico polícromo también fragmentario del Norte de Africa, que pavimentaba una estancia situada frente al triclinium de la Casa de Isguntus en la antigua Hippo Regius, de la primera mitad del siglo III d.C. ${ }^{32}$. Se trata también de un paisaje costero, que conjuga en uno de los fragmentos (Fig. 8) escenas de pesca y en el otro (Fig. 9) la representación de un tritón aproximándose a unas rocas, además de algún crustáceo y varios

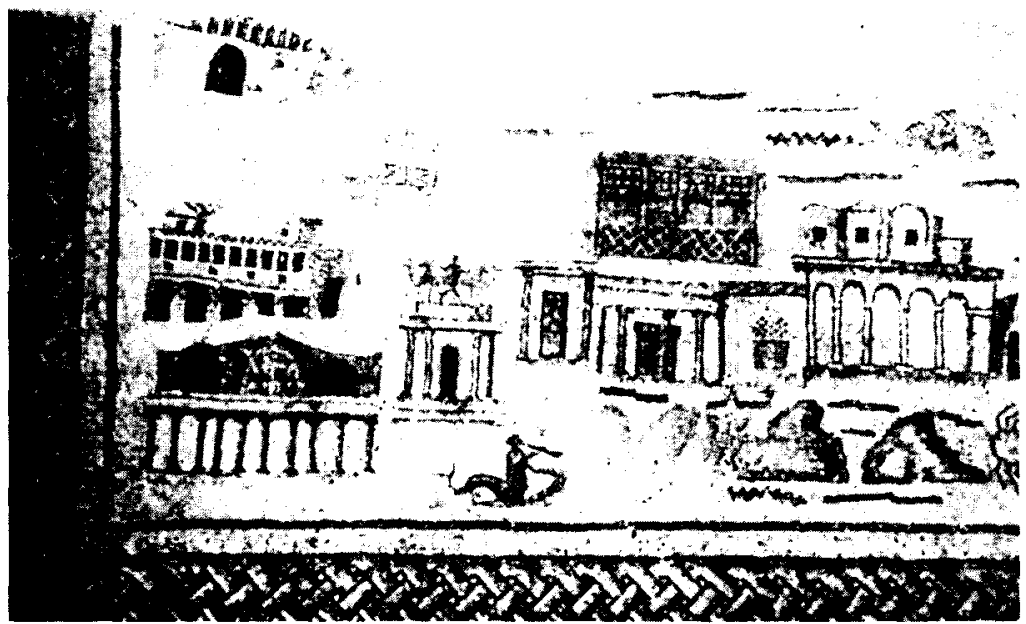

Figura 9. Fragmento del mosaico de Hippo Regius. Foto: Según Marec. 
peces, en un agua indicada mediante trazos de teselas dispuestas sobre la punta en sentido paralelo; mientras en tierra firme se aprecia en el primero un promontorio rocoso con árboles, zona denominada La Roca del León, un gran edificio identificado como el templo dedicado a la Venus marina y cabañas propias de pescadores, y, en el segundo, un puente sobre pilares atravesando un rio que desemboca en el mar, la representación quizás en ese ambiente todavía no urbano del edificio señorial de una villa, y ya junto a la orilla, sin explicitar la línea de costa como en EI Alia, diversos edificios en planos superpuestos para indicar la profundidad. En primer plano, una columnata adintelada, quizá como referencia a la instalación portuaria, sobre ella, indicando un segundo plano, una basílica de tres naves, a la derecha una puerta triunfal sobre estilobato, coronada por un grupo escultórico compuesto por un personaje guiando una cuadriga, y hacia la derecha, adecuándose a la orilla, varios edificios de una sólo planta que parecen dar a una calle porticada, con arquería el de la derecha, sobre el que figura una segunda planta de cubiertas abovedadas, en clara referencia a un establecimiento termal, mientras en un plano más elevado todavía se aprecia otra construcción con celosias, identificada como un mercado.

Tanto E. Marec como G. López Monteagudo ${ }^{33}$ resumen a la perfección la significación de ambos fragmentos al manifestar que sintetizan una visión realista de la ciudad de Hippo Regius y de su territorio en época romana. Por un lado, el área urbana con edificios públicos y privados así como el entorno rural representado por el edificio de la villa y, por otro, la zona sagrada en la colina próxima a la Roca del León, donde se alzaba el templo a Venus marina, y el hábitat de los pescadores ${ }^{34}$, en alusión a su riqueza agrícola y pesquera.

Sin embargo, representaciones de una ciudad maritima que como las de los mosaicos de El Alia e Hippona contengan, aunque sea de modo sintético, reflejos de los principales edificios y su actividad no son habituales. En lineas generales, el resto de las representaciones que pueden ser interpretadas como correspondientes a una ciudad mantima ${ }^{35}$ se limi-

Ibidem: G. Lopez Monteagudo, «Representaciones de ciudades en mosaicos romanos del Norte de África", pág. 1.244

Cabañas de pescadores situadas junto a la costa aparecen también representadas no sólo en el citado mosaico de El Alia, sino también en un mosaico de Sidi Abdallah, en las cercanias de la antigua Hippo Diarrythus, en torno a tinales del siglo $\mathrm{V}$ d.C.. donde igualmente el mar ocupa la mayor parte de la superficie, M. FANTAR et alii. La Mosaique en Tunisie. Túnez 1994, pág. 87.

35 Excluimos de esta consideración representaciones muy inciertas, como la de un mosaico que pavimentaba una fuente poligonal en Carthago ( $M$. FANTAR et alii, op. cit.). donde una serie de edificios situados junto al mar podrían interpretarse como representativos de una ciudad costera 
tan a una vista mucho más parcial y suelen constreñirse a las edificaciones o instalaciones portuarias ${ }^{36}$.

Un ejemplo de este género se encuentra también en la musivaria romana del Norte de Africa, concretamente en el pavimento polícromo que cubria el frigidarium de las termas de Themetra (Fig.10), de principios del siglo III d.C. ${ }^{37}$. Es una gran escena marina, en la que destaca una colosal máscara de Océanos flanqueada por dos navíos en un mar

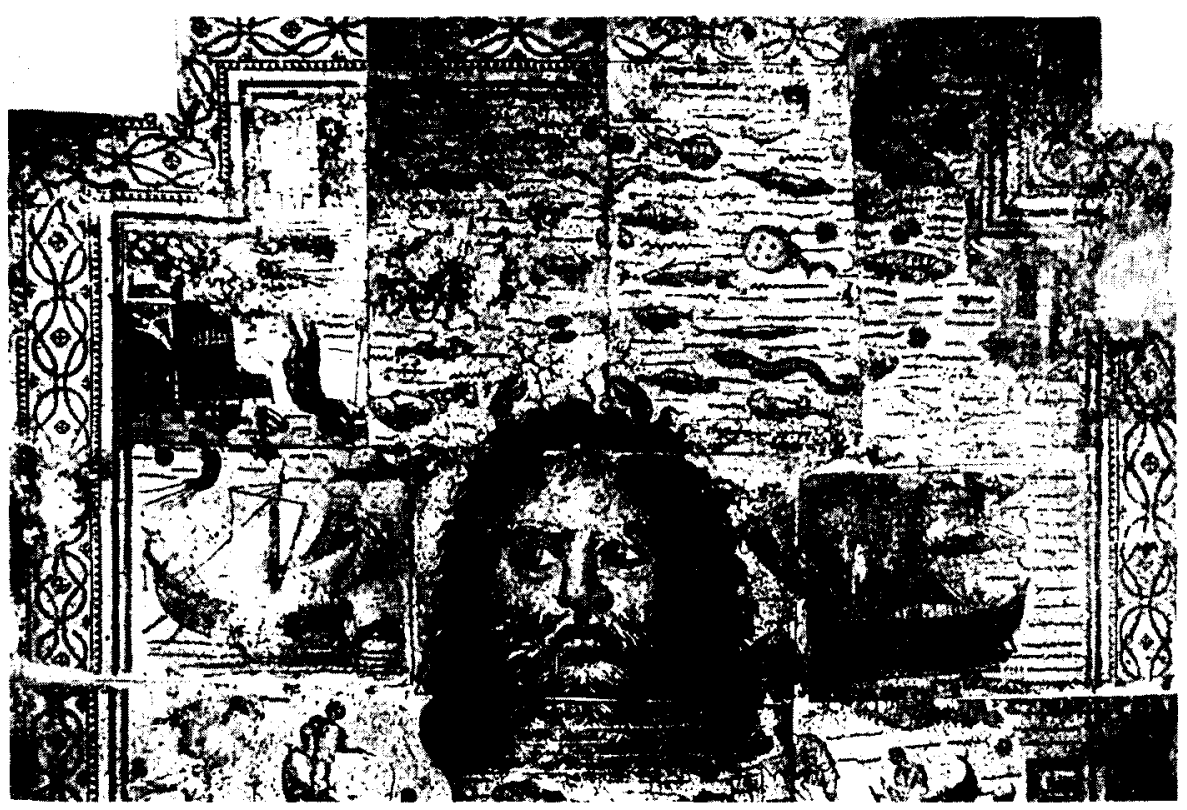

Figura 10. Mosaico de las termas de Themetra. Foto: Según Foucher.

Sin embargo. a nuestro juicio, su unidad arquitectónica y el recurso frecuentemente utilizado por los mosaistas de presentar en el mismo primer plano fachada y laterales de un mismo edificio o sus estancias interiores en el exterior nos inclinan a considerar dicha representación como exponente de una villa maritima. En este mismo sentido, la incertidumbre se cierne sobre representaciones como las que decoran la orla de un mosaico de la Casa del Asno en Cuicul (M. BLANChard Lemet, Maison a mosaiques du quartier central à Djemila (Cuicul). Aix-en Provence 1978, págs. 65-84, láms. I, VI. $x$ y XIV) por ejemplo con erotes desembarcando en un edificio. que aún representativo de la arquitectura de la Antigüedad Tardia, no podemos afirmar que corresponda a la representación de una ciudad: o las muy similares documentadas en mosaicos de Piazza Armerina (A. Carianisin! et alii. Filosotiana. La Villa de Piazza Armerina. Palermo 1982, pág. 250 y ss.).

No incluimos en este estudio representaciones aisladas de faros, sino aquellas en las que se puede apreciar la diversidad de edificios portuarios pertenecientes a una ciudad maritima $\mid x$ y $\times|| \mid$

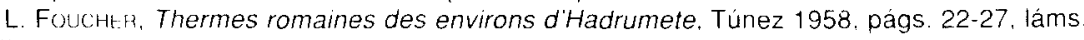


repleto de diferentes especies. Los trazos indicativos del agua se disponen en sentido horizontal y cubren toda la superficie del campo, según una visión aérea en vertical. Sin embargo, en los laterales y con una orientación opuesta a la máscara, algunas construcciones portuanas han sido figuradas a ras de tierra con una visión angular. En uno de los lados se ha representado un edificio almenado (Fig. 11) que tiene varios pisos, el primero con galería porticada, bien visible en la fachada orientada al mar, y el superior con gran balconada volada, sustentada por cinco vigas que arrancan del muro, así como una torre cubierta por un tejado a cuatro aguas que se destaca en uno de los extremos. Ade-

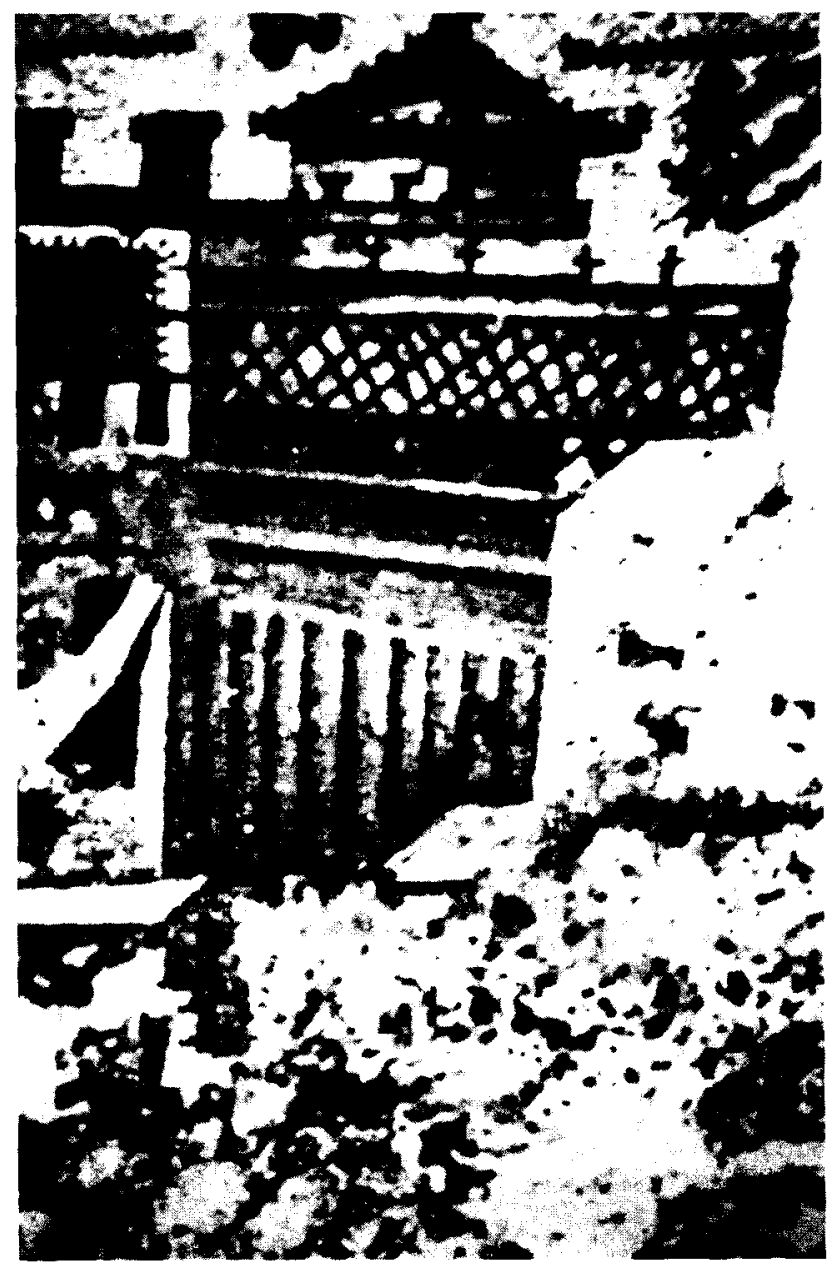

Figura 11. Mosaico de las termas de Themetra. Detalle. Foto: Según Foucher. 


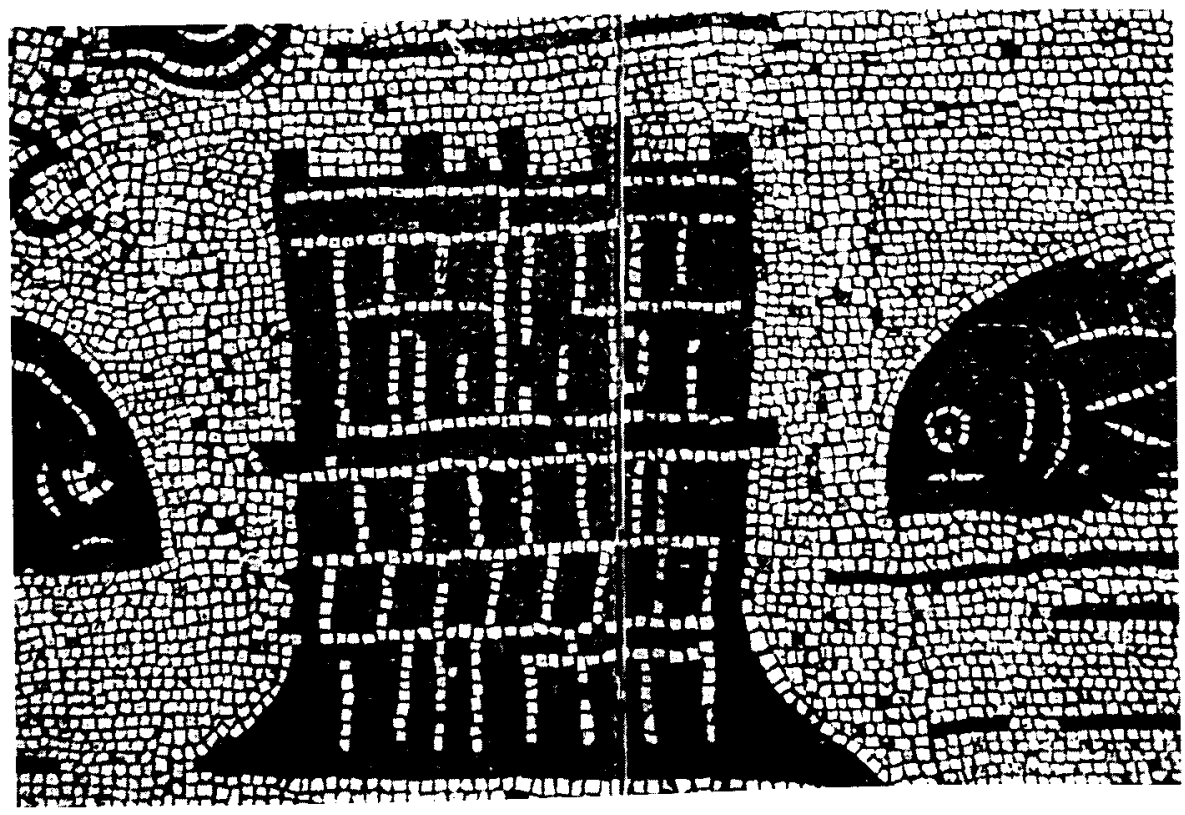

Figura 12. Mosaico del Foro de las Corporaciones (Ostia). Detalle. Foto: Según Becatti.

cuándose al otro ángulo del mismo lado figura también un torreón igualmente almenado de planta cuadrada, que recuerda tanto por su forma como por el punto de vista angular, según el cual ha sido representado, al torreón que aparece flanqueado por dos peces en un mosaico bícro mo del Foro de las Corporaciones en Ostia ${ }^{38}$ (Fig. 12) y a la torre documentada en la escena de Hero y Leandro en un pavimento termal de Thaenae ${ }^{39}$, cuya función debía ser la de una torre de vigilancia (Fig 13). Finalmente, en el lado opuesto, otro edificio más pequeño, del que se ve su fachada y un lateral, con cubierta a dos aguas y frontón coronado por cuernos de ciervo, del mismo tipo que los representados en el mosaico de El Alia.

Construcciones a la orilla del mar y un busto de Océanos se documentan también en el pavimento de un triclinium absidado perteneciente a la villa de Bad Kreuznach (Fig. 14), que data de mediados del siglo III d.C. ${ }^{40}$.

G. BECATIL op. cit., pág. 68. núm. 92. tav. CLXXVIII

R. MAssigu, Le Musée de Stax, Paris 1912, págs. 1-5. láms. I-IV

G. HELLENKEMPER. "Neue römische Mosaiken in Deutschland. Beiträge zur Chronologie des 3. Jahrhundertes", III CIMA, Rávena 1983, págs. 344-345, tigs. 6-7. 


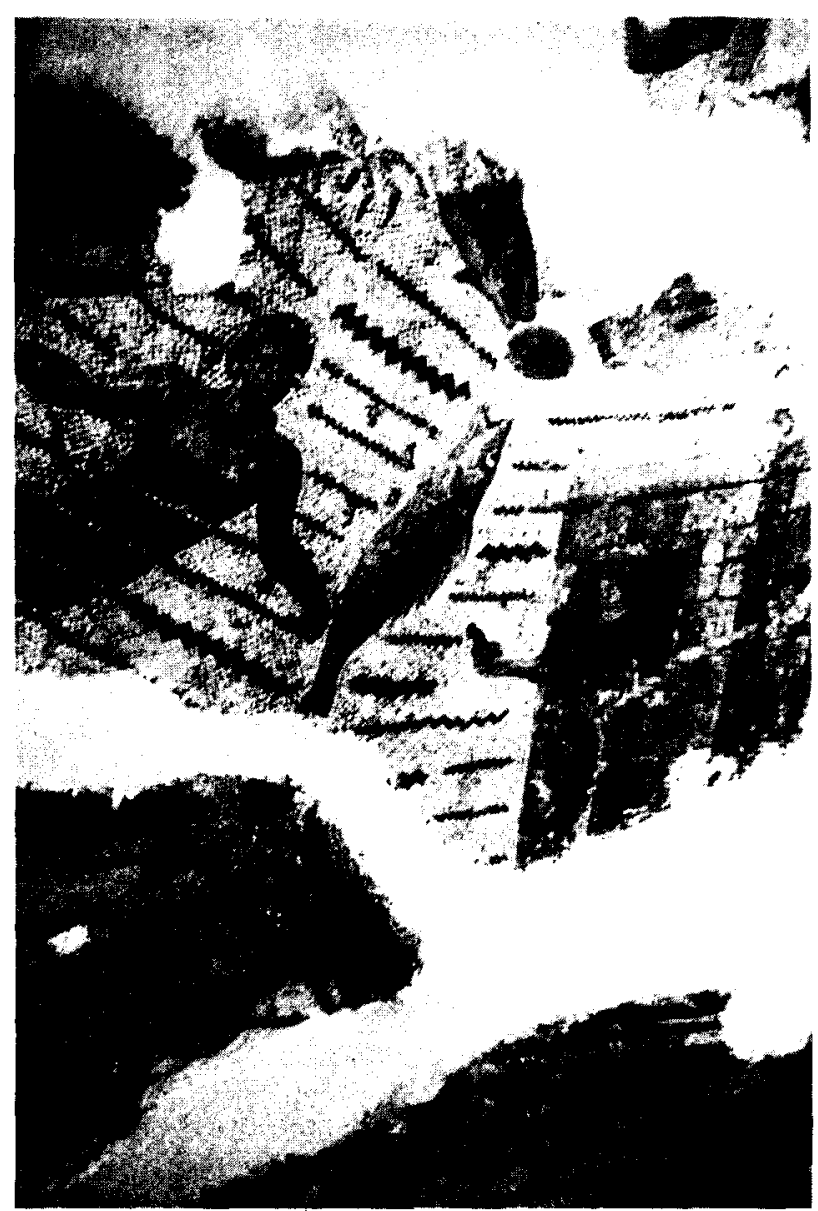

Figura 13. Mosaico de las termas de Thaenae. Detalle. Foto del autor.

Océanos decora aquí la zona absidada, mientras son numerosísimas las especies marinas figuradas en el agua que, mediante líneas de diminutos trazos horizontales alternando con otras de trazos verticales, cubre toda la superficie del mosaico, dispuesto en torno a un hexágono situado en el centro de la estancia como perímetro de una fuente. Completan la decoración del pavimento algunos barcos y tres grupos de edificios situados en el centro de cada uno de los tres lados rectilíneos.

En el lado opuesto al ábside destaca con una orientación hacia el exterior un primer grupo de edificaciones que se asientan sobre un terreno 


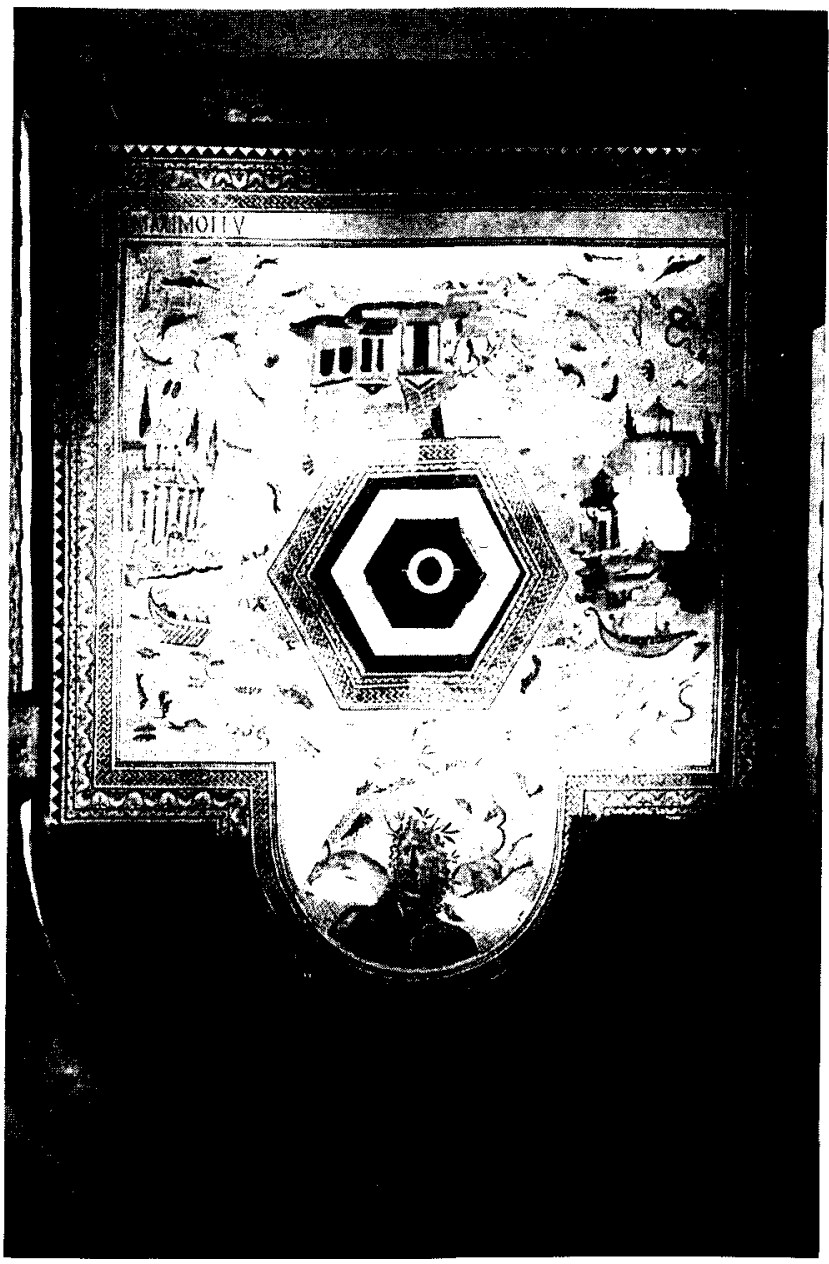

Figura 14. Mosaico de Bad Kreuznach. Foto: Cortesia G. López Monteagudo.

rocoso (Fig. 15), en cuyas cercanías pescaban desde dos barcas al menos cuatro personaj es. La representación de uno de los edificios responde a la combinación de dos puntos de vista diferentes, ya que se muestra froritalmente la fachada, con vano adintelado y dos columnas sustentando el frontón, y al tiempo, con un punto de vista más elevado, se representa el tejado a dos aguas, cuya longitud da idea de la profundidad del edificio. Junto a éste se alza otro edificio muy similar y entre ambos, en segundo plano, el lateral de un tejado a dos aguas correspondiente a una tercera construcción. 


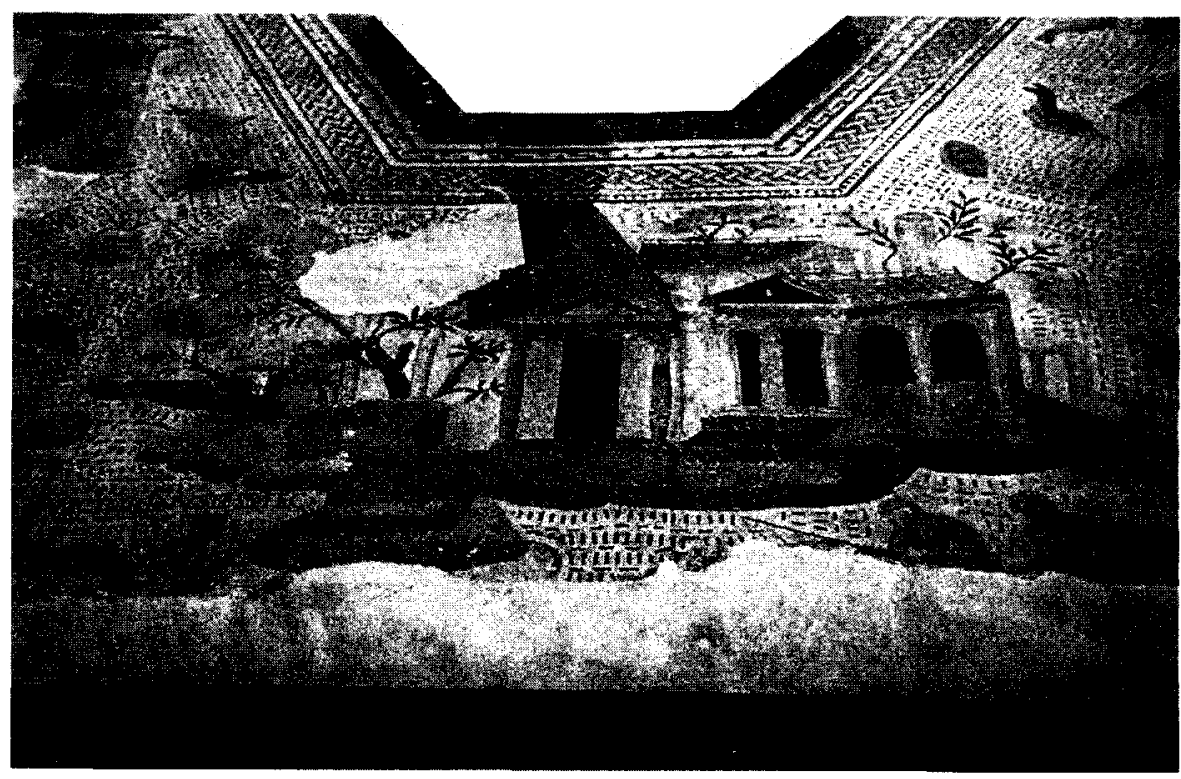

Figura 15. Mosaico de Bad Kreuznach. Detalle. Foto: Cortesia G. Lopez Monteagudo.

El segundo edificio, cuya visión angular refleja la representación de un lateral con ventanas arqueadas, que aparecen flanqueadas por columnas, sólo se distingue del primero al presentar dos peldaños de acceso al vano que da paso al interior, según un modelo bien documentado en las representaciones portuarias ${ }^{41}$.

Con otra orientación, la misma que presenta el busto de Océanos, los dos grupos restantes se sitúan en los laterales del mosaico. En el lado izquierdo (Fig. 16), una nave con cinco tripulantes surca el mar en las proximidades de la costa, donde sobre una zona también rocosa figuran tres hombres, dos de ellos parecen intercambiarse algo junto a las conchas de unos moluscos, quizás la compra de mejillones al vendedor sentado sobre una roca, mientras el tercero aparece asiendo una de las tres ánforas colocadas de pie en un pequeño recinto, bien delimitado por una barandilla. Ambas escenas, propias de un ambiente portuario, transcurren junto a un gran edificio situado en un segundo plano. Su forma responde a las galerías porticadas, sustentadas por columnas y cubiertas por techumbre a doble vertiente, que parecen bordear un espacio a cielo abier-

Véase más adelante. 

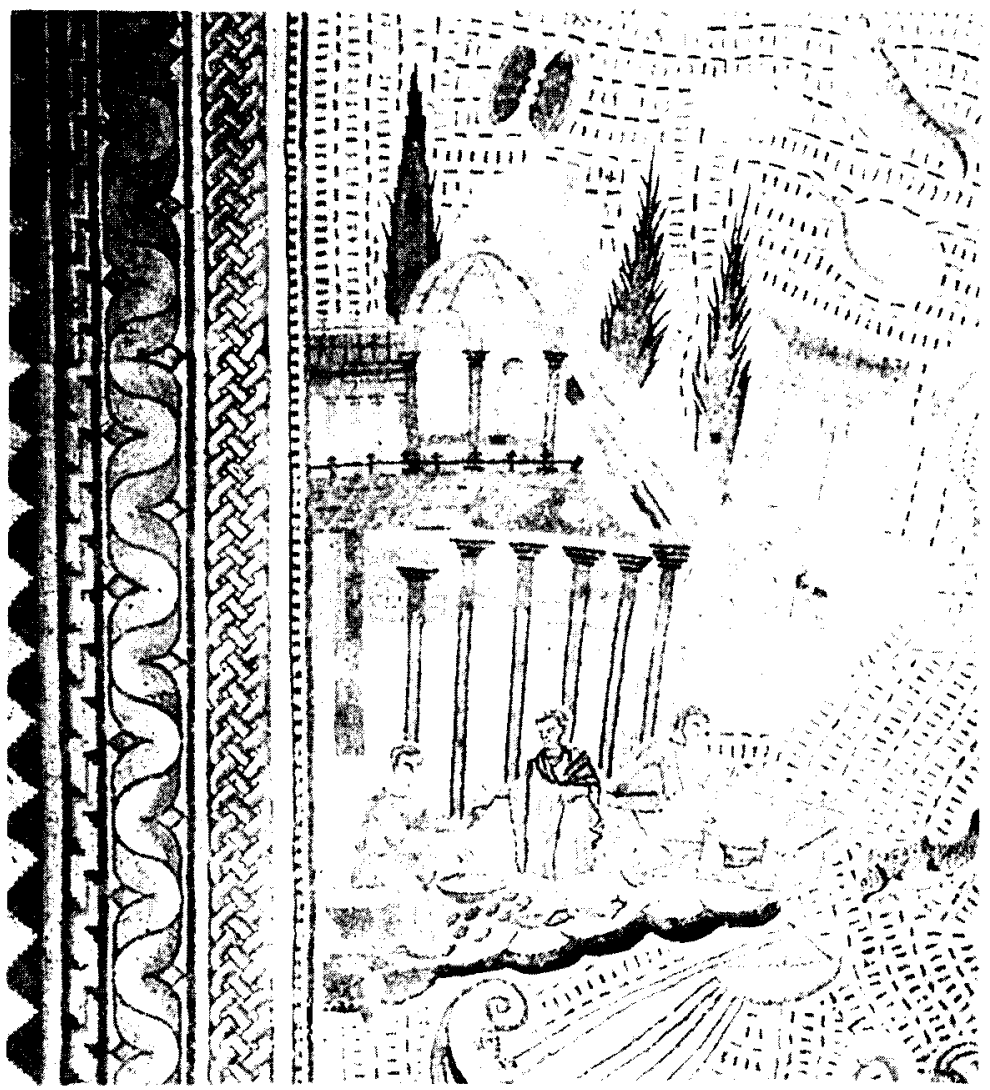

Figura 16. Mosaico de Bad Kreuznach. Detalle. Foto: Cortesia G. López Monteagudo.

to, en estrecha similitud con la representación de un puerto en los paneles de pasta vítrea hallados en Kenchreai ${ }^{42}$ (Fig. 17); destacando en uno de los extremos confluyentes una edificación de planta centralizada y cubierta abovedada que reposa sobre arquerías sustentadas por columnas. Muy próxima, en la orilla se observa vista de perfil, casi dando la espalda, y con una postura extremadamente encorvada, la representación de una estatua de Neptuno, portando sus tradicionales atributos, el tridente y un pequeño delfín, y al fondo una extraña construcción cuadrada con tres columnas y una especie de barandilla en la parte superior, cuya representación quizá responda a la combinación de distintos puntos de vista. 


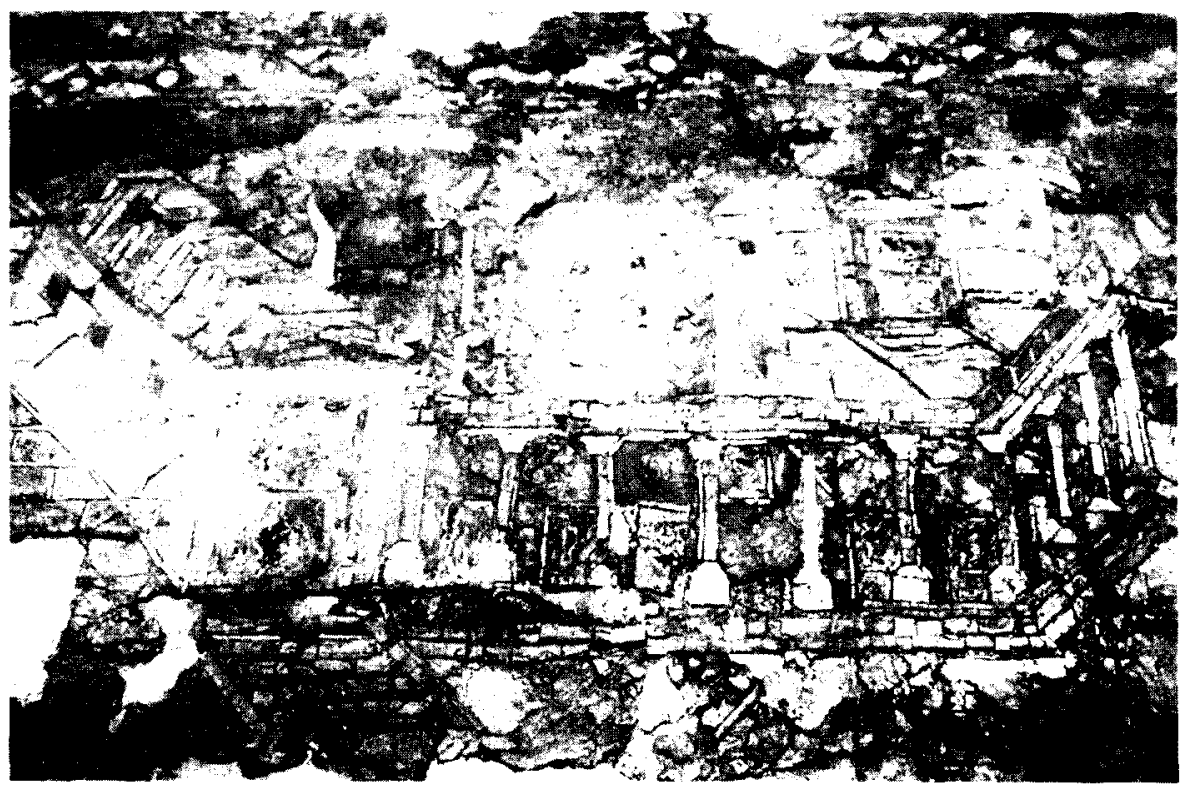

Figura 17. Paneles vidriados de Kenchreai. Detalle. Foto: Cortesía G. López Monteagudo.

En el lado derecho (Fig. 18) se alza otra edificación del mismo tipo, pero vista desde otro punto y a altura más elevada. Se trata de galerías porticadas con cubiertas a dos aguas que bordean un recinto al aire libre. En el lado más próximo al espectador, muy afectado por una laguna, son adinteladas y en el opuesto, situado en segundo plano, elevadas y estrechas arquerías, tras las que destaca la parte alta de una torre con tejado a cuatro aguas. A pesar del deterioro también se aprecia en el ángulo izquierdo un edificio de mayor altura, con cubierta a dos aguas y un vano adintelado de entrada, que aparece protegido por una especie de voladizo en forma de toldo, y en el extremo inferior derecho, al nivel de las rocas más próximas al agua, un muro con cuatro ventanas arqueadas. Muy cerca, sobre el escalonado terreno rocoso figura de pie un personaje que tira de la caña para sacar del agua la especie capturada, mientras un barco (Fig. 19) con dos tripulantes transporta como mercancia cuatro ánforas idénticas a las que aparecen en el puerto representado en el lado izquierdo del mosaico.

El pavimento de la villa de Bad Kreuznach no es, sin embargo, el único que contiene la representación explicita de varios puertos, ya que la musivaria romana de Hispania ofrece una de las más completas representaciones de paisajes portuarios. Nos referimos a uno de los mosaicos ha- 


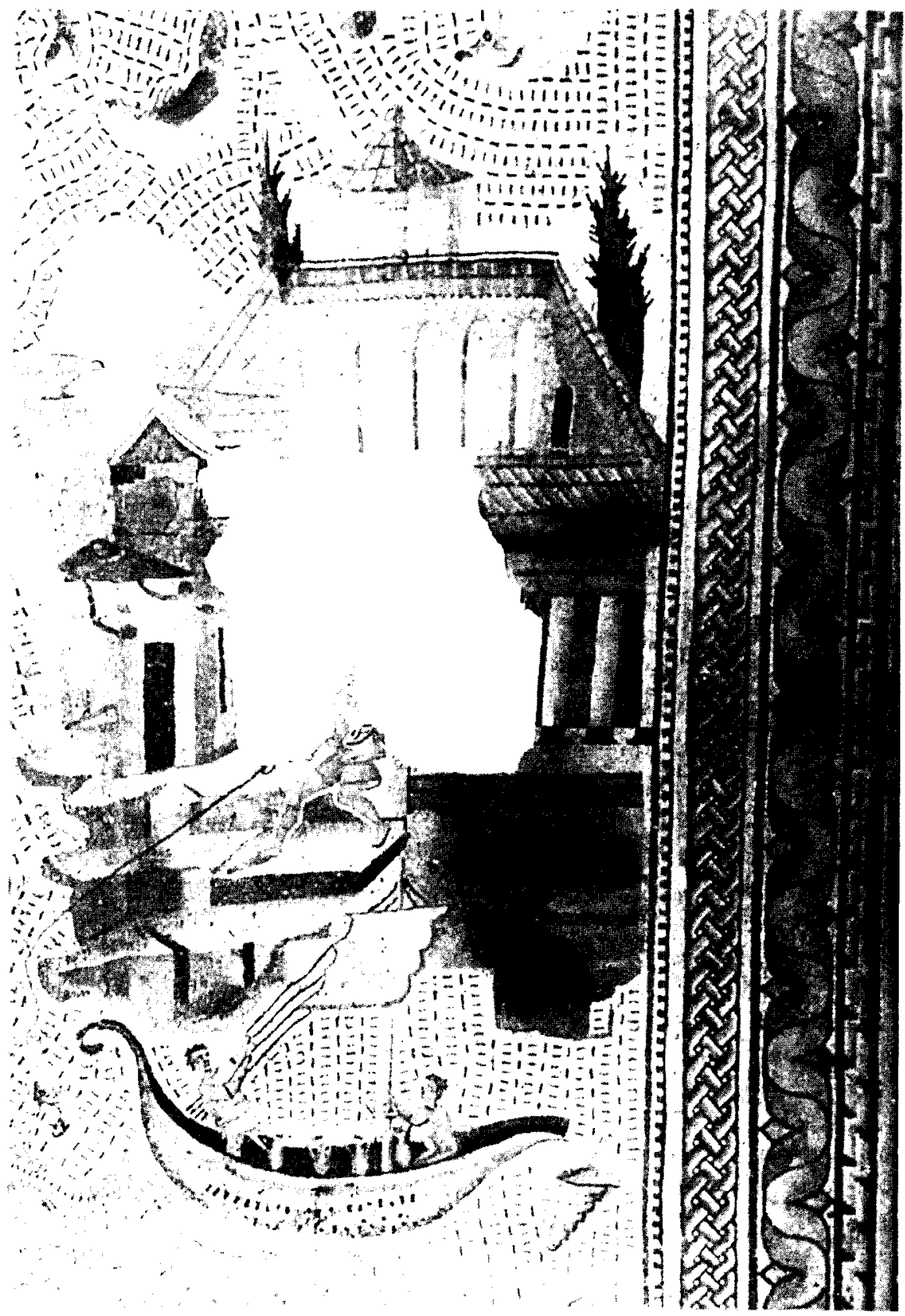

Figura 18. Mosaico de Bad Kreuznach. Detalle. Foto: Cortesia de G. Lopez Monteagudo. 


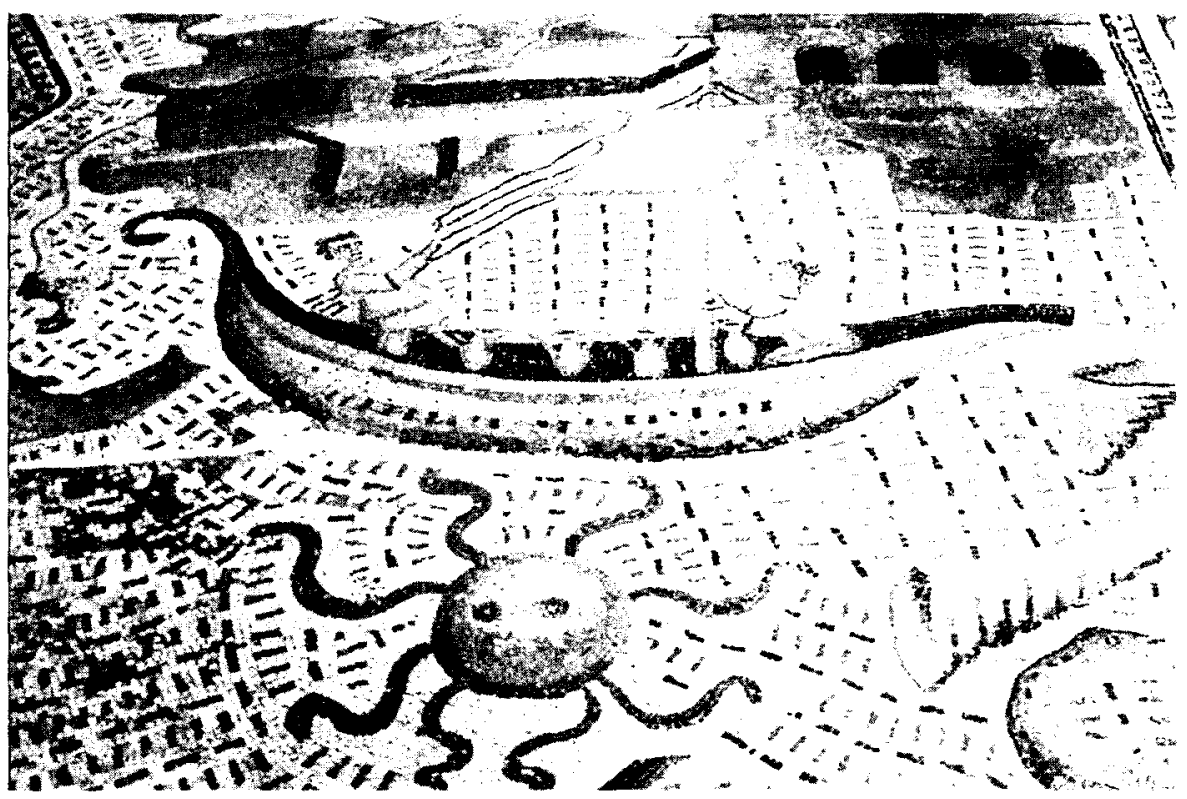

Figura 19. Mosaico de Bad Kreuznach. Detalle. Foto: Cortesia de G. López Monteagudo.

Ilados en la Vega Baja deToledo ${ }^{43}$ (Fig. 20), de finales del siglo III o principios del IV d.C., que servía de pavimento a una fuente de planta octogonal correspondiente al perístiio de una villa. Sus representaciones bordean de cara al exterior el espacio central, muy afectado por una laguna que se cierne también sobre una parte del pavimento, incitando al espectador a un recorrido alrededor de la fuente para poder contemplar las diversas escenas.

En contraste con otras representaciones de paisajes costeros y portuarios, el agua no figura expresamente indicada por trazos de teselas, ni existe delimitación precisa sobre las zonas costeras o de tierra firme, ya que tanto los barcos y las especies propias del ambiente marino como los edificios y personajes, que por su actividad se sobreentienden situados en la costa, figuran sobre un fondo neutro de teselas blancas. Es, por tanto, el propio carácter de las representaciones el que precisa tanto el contexto costero como el marino.

J.M. Blazour Z, Mosaicos romanos de la Real Academia de la Historia, Ciudad Real, Toledo, Madrid y Cuenca. CME V. Madrid 1982, núm. 25. 


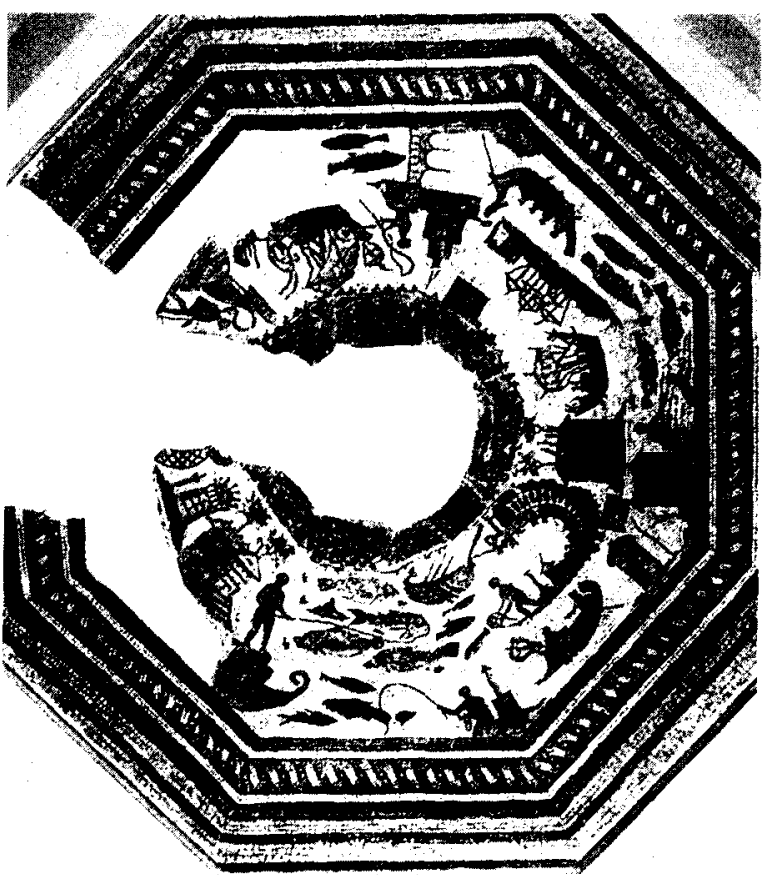

Figura 20. Mosaico de la Vega Baja de Toledo. Detalle. Foto: Cortesia de J.M. Blázquez.

Partiendo de la zona afectada por la laguna, de izquierda a derecha (Fig. 21) se aprecia una columna, así como una construcción de planta circular y forma cilindrica, carente de cubierta, que presenta al menos tres pisos con pequeñas ventanas y resaltes en la parte alta. La identificación de este edificio es incierta. Podría tratarse de una torre de vigilancia, aunque en la línea señalada por Balil ${ }^{44}$, quien, por su emplazamiento junto a una columna y al templete situado a continuación, apuntó su relación con un lugar de culto, su similitud con los edificios cilindricos documentados en el mosaico de El Alia y en el citado fresco de la Via Appia indica un carácter sagrado en estrecha conexión con los escenarios marítimos y portuarios. Le sigue un edificio que respondiendo a una visión angular muestra tres pisos, el de entrada y dos más, bien delimitados por cornisas, con pequeñas ventanas tanto en la fachada como en el lateral representado y una cubierta a doble vertiente con frontón coronado por cornamentas de

A. Bal. IL, "Monumentos alejandrinos y paisajes egipcios en un mosaico romano de Toledo (España)". Studi in onore di Achille Adriani 3, Roma 1984. págs. 433439 


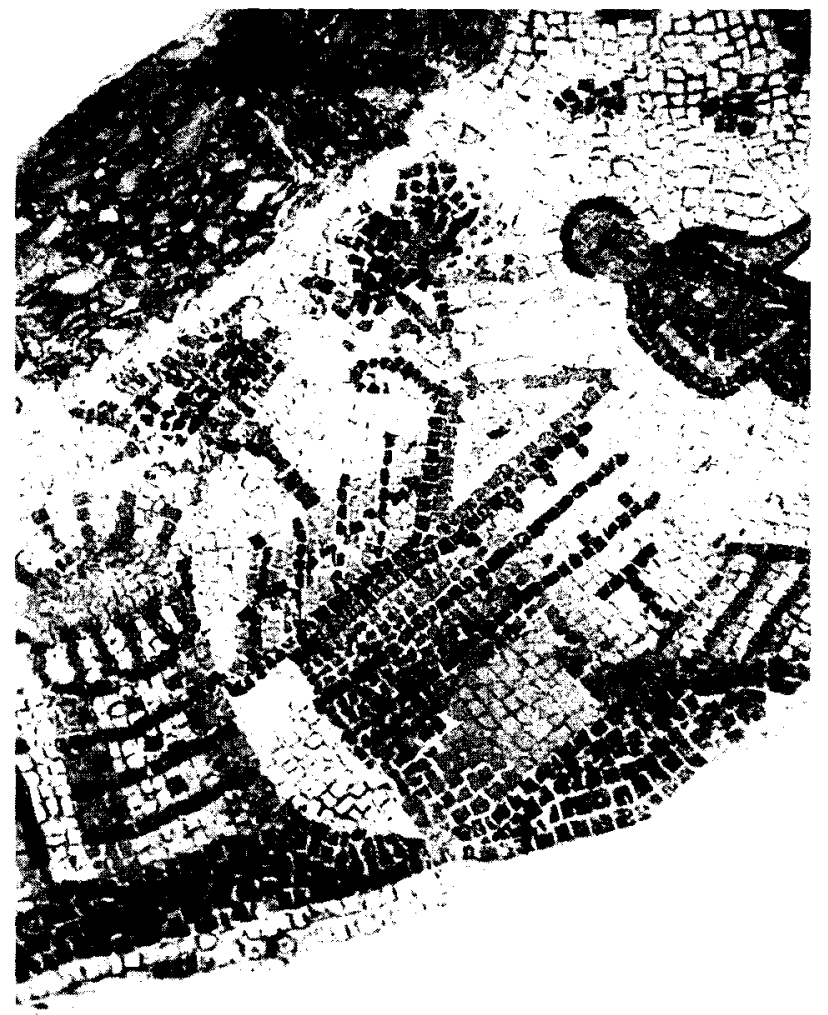

Figura 21. Mosaico de la Vega Baja de Toledo. Detalle. Foto: Cortesia de J.M. Blázquez.

ciervo, aunque lo más destacable es el tramo de peldaños que conduce al vano de acceso al interior. Edificios de este tipo aparecen representados en obras de época helenística, en los mosaicos de El Alia y Bad Kreuznach y en otros más tardios, así como en los paneles vidriados de Kenchreai, entre otros, donde ocupando un lugar primordial en las representaciones portuarias han sido identificados como santuarios.

Tras estas construcciones, el mar figura surcado por dos barcas y distintos peces hasta la representación de otro escenario costero, indicado por un pedestal cilíndrico sobre el que se alza de nuevo una columna, a cuya vera se asienta un pescador que lanza su caña al mar (Fig. 22). En las proximidades, una construcción porticada con pabellones en los extremos, con perspectiva aplanada, que responde a la forma semicircular propia de muchas representaciones de puertos como la citada en el mosaico de El Alia; un edificio de planta circular y forma cilindrica con cubierta có- 


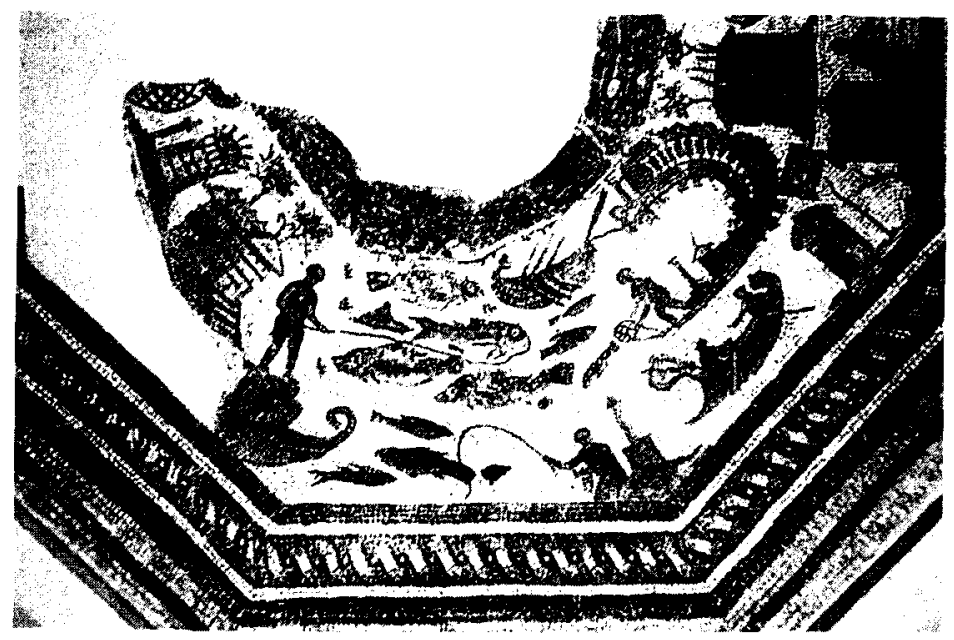

Figura 22. Mosaico de la Vega Baja de Toledo. Detalles. Foto: Cortesía de J.M. Blázquez.

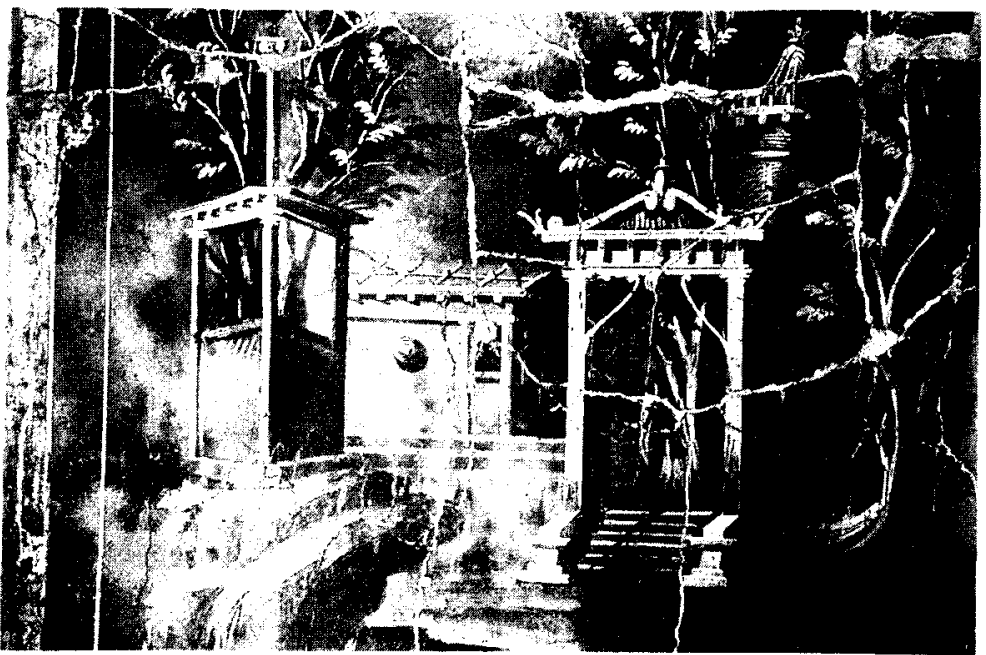

Figura 23. Pintura de Herculano. Foto: Segün J. Charbonneaux et alii.

nica de carácter sacral, cuyas representaciones se documentan ya en varias pinturas, como la realizada sobre mármol procedente de Herculano (Fig. 23), que refleja un paisaje con varios edículos ${ }^{45}$, y otras dos también 
del sigio I d.C. y de contexto sacro-idílico ${ }^{46}$ (Fig. 24), así como en algunos mosaicos hispanos, donde, no obstante, no deben ser interpretadas como chozas típicas de paisajes nilóticos ${ }^{47}$; un rectángulo lleno de agua, que ha sido identificado con un ostraria ${ }^{48} ; y$ dos edificios muy similares al identificado como santuario.

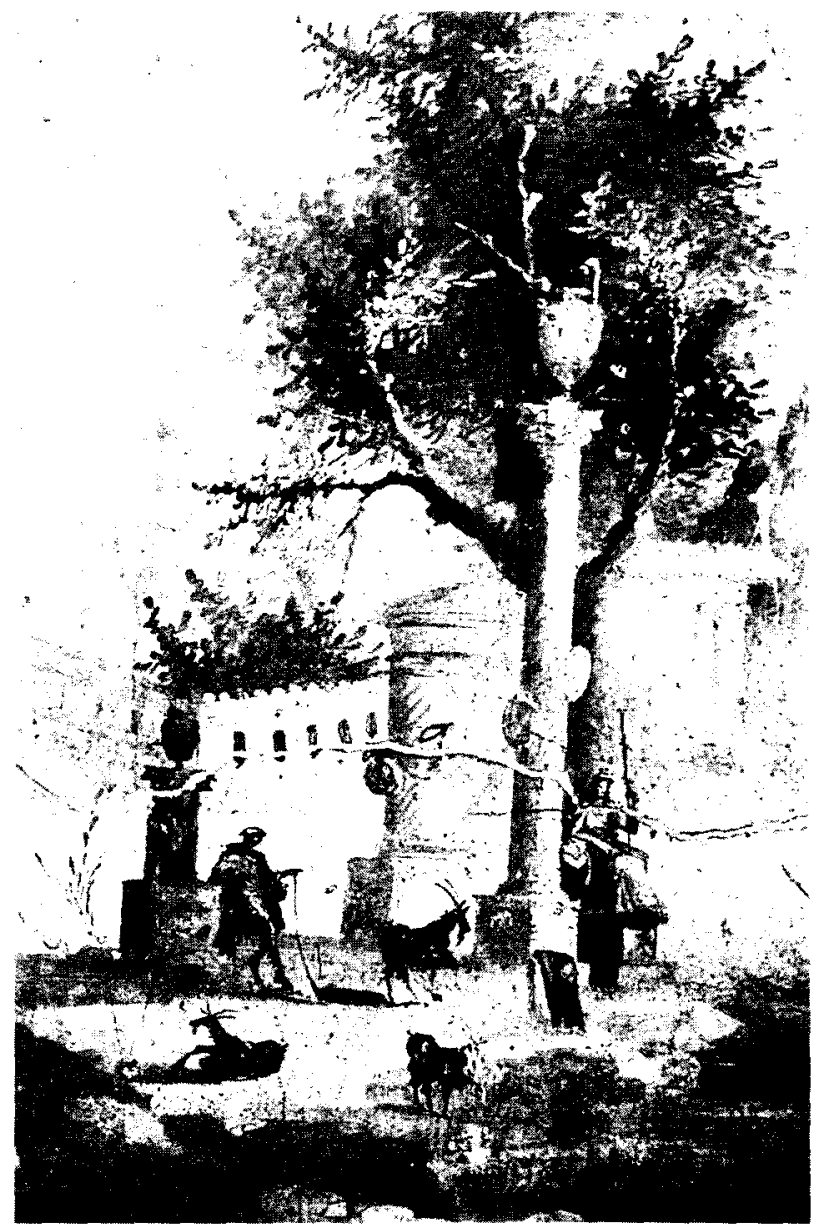

Figura 24. Pintura de Boscotrease. Foto: Segün R. Turcan.

R. TuRCan. L Art Romain..., figs. 69 y 72

En este sentido, véase lo expuesto por G. LoH l. MONIE AGUuo. "Representaciones...". págs. 1253-54.

48. lbidem. pág. 1.253, nota 41. 


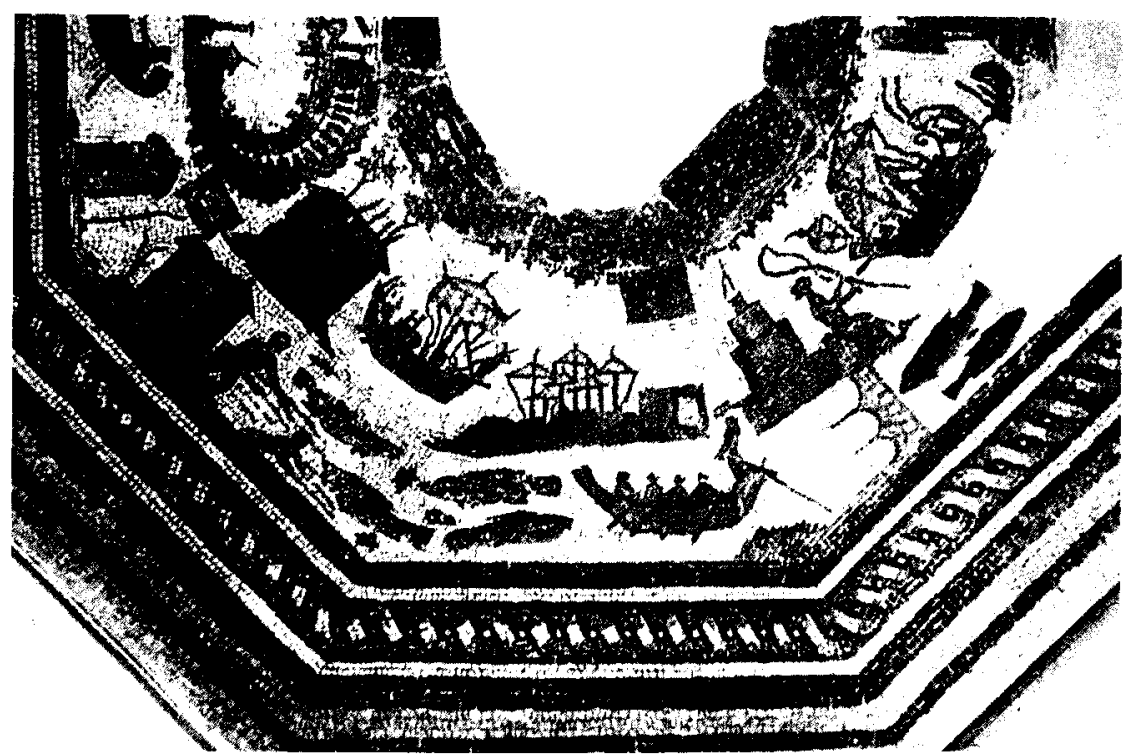

Figura 25. Mosaico de la Vega Baja de Toledo. Detalle. Foto: Cortesia de J.M. Blázquez.

A continuación (Fig. 25) aparece de nuevo el mar y la representación de varias naves y diversos peces, así como otro puerto, simbolizado por un faro de varios cuerpos con alumbrado, muy similar a la representación de un mosaico bicromo de Ostia ${ }^{49}$, y por un muelle sobre arquerías, reflejado con una perspectiva aplanada como si estuviera caido sobre el agua, que parte del mismo basamento sobre el que se erige el faro. Son las mismas estructuras arquitectónicas que aparecen, aunque representadas desde otro punto de vista, en un escenario portuario de un mosaico polícromo de fines del siglo ॥ d.C. conservado en el Antiquarium Comunale ${ }^{50}$ (Fig. 26), donde destacan en primer plano las arquerías del muelle y a la izquierda, sobre un gran basamento, un elevado faro que presenta un primer cuerpo de planta cuadrada y un segundo cuerpo circular con techumbre cónica, de menor altura, coronado por una estatua, mientras en un plano más lejano figura una gran nave en el mar.

Sobre el muelle figura sentado un pescador, orientado hacia el siguiente espacio dominado por un mar surcado por una gran nave.

G. BICATTI, Op. cit., núm. 123.

M. RE DOF, op. cit, pág. 854 


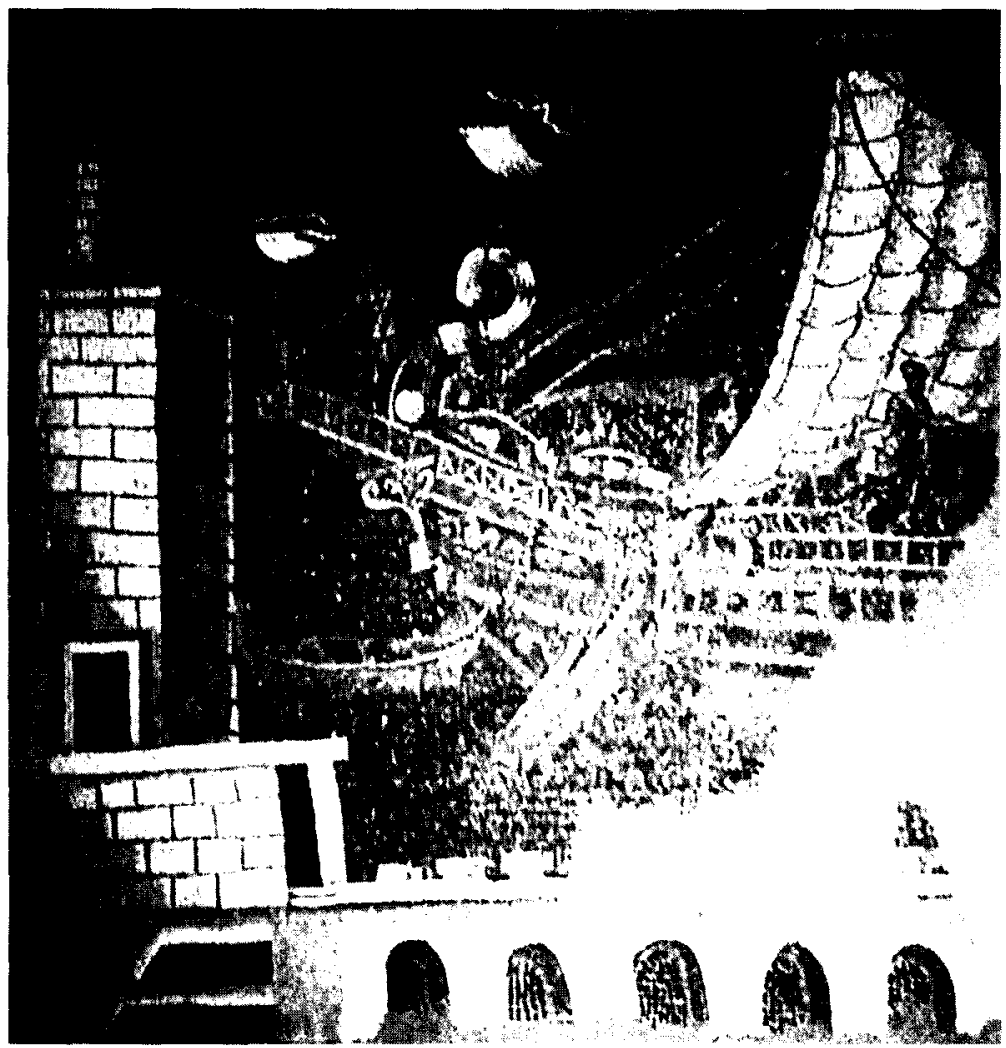

Figura 26. Mosaico del Antiquarium Communale. Foto del autor

Sigue un punto costero, a juzgar por la representación de un timón y un aplustre rematado por una cabeza de cisne que son elementos típicos de un trofeo naval erigido como simbolo de una victoria y un personaje en actitud de tirar de la red que se conserva tras la laguna (Fig. 27).

El mosaico de la Vega Baja es, por tanto, un rico repertorio de representaciones portuarias, en el que mediante la combinación de varias escenas de tradición alejandrina se podría haber pretendido sintetizar no sólo el ambiente marino y distintos puertos, sino quizás también el propio mar Mediterráneo en torno al cual, salpicado por diferentes puertos, giraba la vida en el Imperio.

Como último exponente de paisajes portuarios, una representación más constreñida se documenta en uno de los rectángulos de un mosaico polícromo que pavimenta una sala absidada del edificio denominado del "tri- 

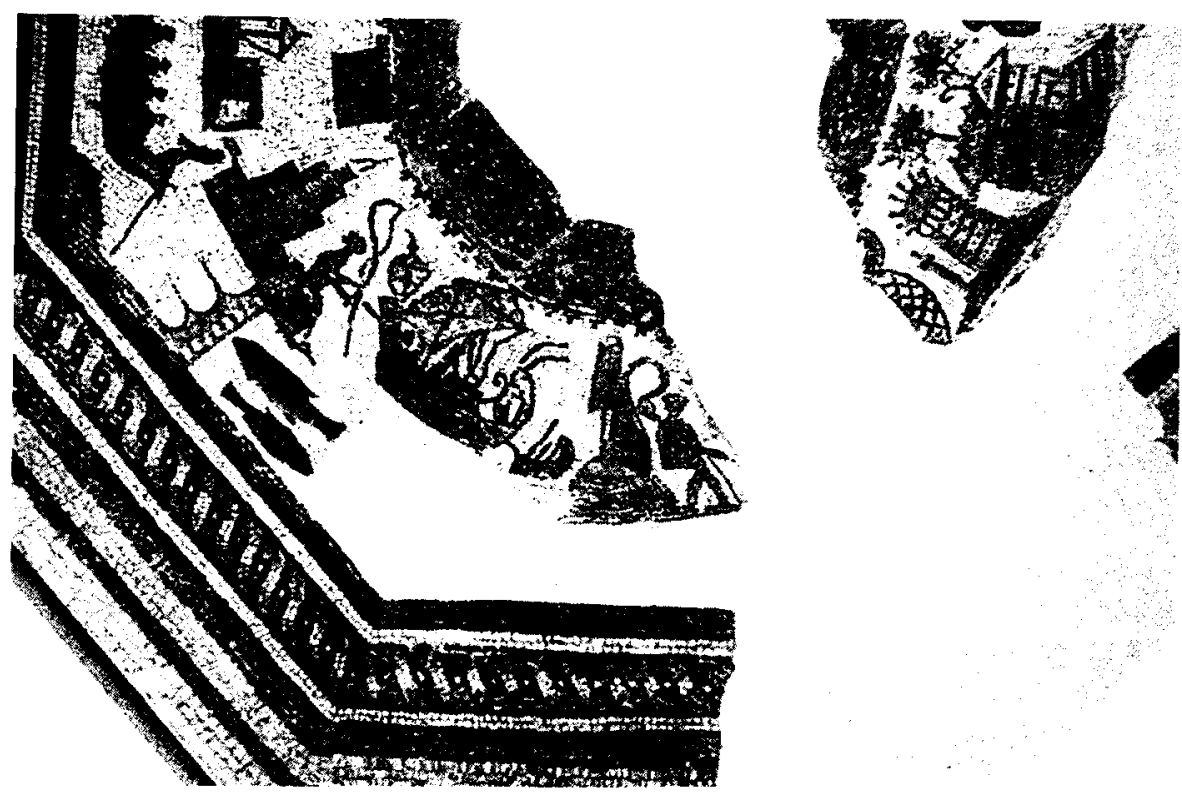

Figura 27. Mosaico de la Vega Baja de Toledo. Detalle. Foto: Cortesia de J.M. Blázquez.

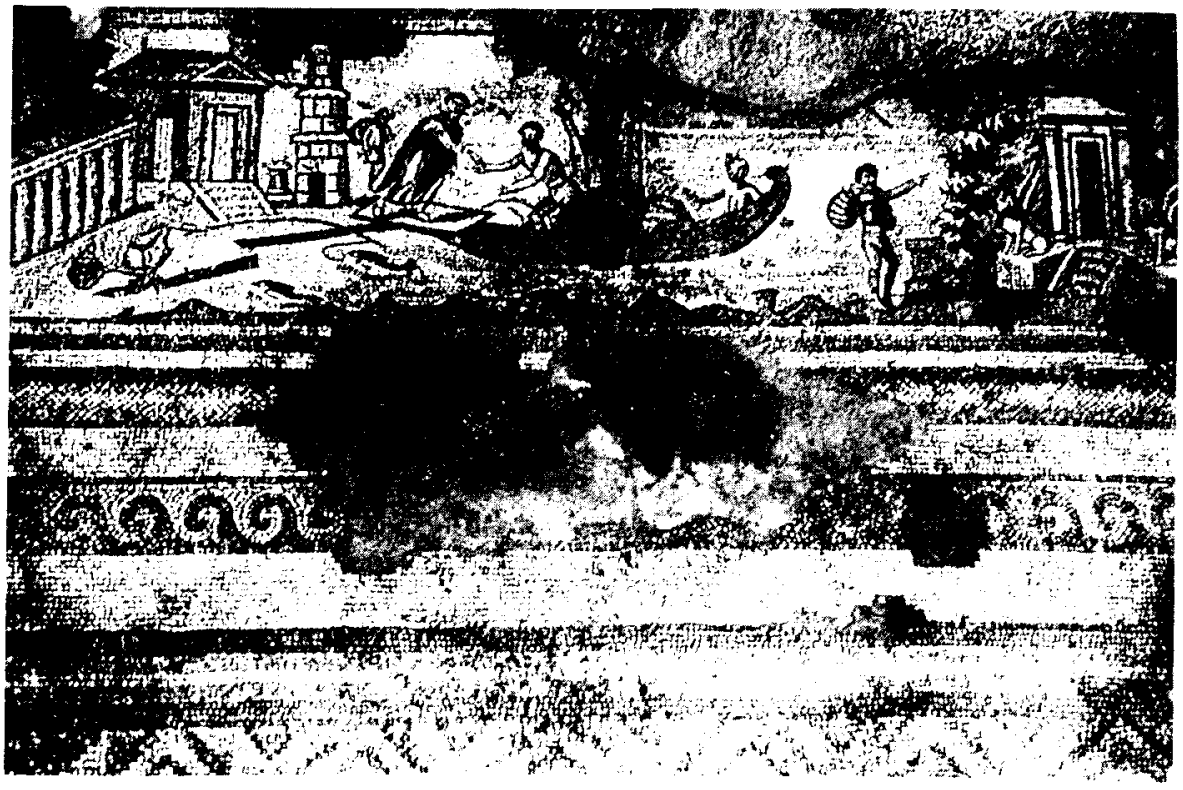

Figura 28. Mosaico de Apamea. Detalle. Foto: Segun Balty. 
Clinos" en Apamea (Fig. 28), fechado en el segundo cuarto del siglo IV d.C. ${ }^{51}$. En la parte izquierda y junto a la línea de costa figuran tres edificios, los dos primeros con una visión angular que nos muestra la galería porticada del primero y la fachada y un lateral del segundo, ambos con techumbre a doble vertiente. Este último edificio presenta una escalinata de varios peldaños como acceso al gran vano adintelado de entrada y ha sido identificado como un santuario de los ya documentados en anteriores mosaicos. Muy próxima se alza una construcción de tres cuerpos, el inferior de planta cuadrada con vano de acceso adintelado y el superior de base circular, que es identificada como un faro. En el centro de la composición predomina el mar, en cuyas aguas se sitúa una barca en la que ya se encuentra acomodado un personaje y otro figura en actitud de ayudar a embarcar en la orilla del faro a un tercer pasajero. Mientras, en el extremo derecho del panel (Fig. 29), otro personaje situado en la orilla opuesta se dirige, señalando con su mano derecha en esa dirección, hacia un edificio afectado por una laguna en su parte superior que, igualmente dotado de peldaños de acceso a la puerta de entrada y flanqueado por dos estatuas de grifos alados, es interpretado como representación de otro santuario.

Queda, por tanto, constancia de unas caracteristicas comunes en las representaciones de ciudades marítimas y paisajes portuarios, ya que

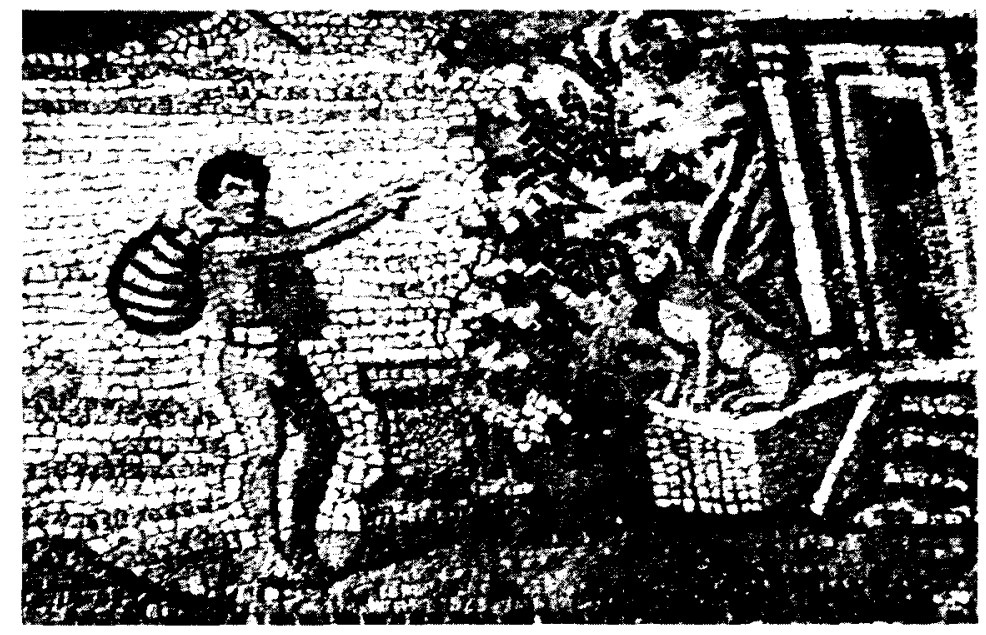

Figura 29. Mosaico de Apemea. Detalle. Foto: Según Balty.

J. Ch. BAl IY, "L'edifice dit "au triclinos», Colloque Apamee de Syrie. Bilan de recherches. 1969. págs. 109-111, láms. XLII-XLIII. 
salvo excepciones relativas, como determinado intento por representar monumentos o lugares típicos de una ciudad real en algunos de los reflejados en el mosaico de Hippo Regius, se aprecia una tendencia generalizada a reproducir aún en contextos paisajísticos distintos y en mosaicos de diferentes épocas arquitecturas genéricas que debieron ser propias de conjuntos urbanos situados junto al mar y emplazamientos específicamente portuarios. No obstante, junto a los más frecuentemente difundidos no sólo en la musivaria, como galerías porticadas, columnas, santuarios, faros y muelles, es de resaltar la representación de algunos edificios, como las construcciones cilíndricas conteniendo o no árboles y columnas, que, aún correspondiendo a imágenes de género, debieron formar parte del paisaje marítimo en la Antigüedad. 